\title{
A systematic review on 1,8-naphthalimide derivatives as emissive materials in organic light-emitting diodes
}

\author{
Sneha Kagatikar ${ }^{1}$ and Dhanya Sunil ${ }^{1, *}$ (1) \\ ${ }^{1}$ Department of Chemistry, Manipal Institute of Technology, Manipal Academy of Higher Education, Manipal, Karnataka 576104, \\ India
}

Received: 8 August 2021

Accepted: 7 October 2021

Published online:

3 January 2022

(C) The Author(s) 2021

\begin{abstract}
Organic light-emitting devices (OLEDs) have garnered significant research attention owing to their immense application prospects in leading technologies for full-color flat panel displays and eco-friendly solid-state lighting. They demonstrate exceptional features such as mercury-free construction, wide viewing angle, superior color quality and captivating flexibility. The requirements of light-emitting organic materials pertaining to high stability, lifetime and luminescence quantum yield, combined with the fabrication of devices with high performance efficiency, are highly challenging. Rational molecular design of 1,8-naphthalimide (NI) derivatives can offer quite promising results in achieving standard-light-emitting materials with a wide range of colors for OLED applications. This review is mainly focused on the synthesis and usage of varyingly substituted NI frameworks as luminescent host, dopant, hole-blocking and electron-transporting materials for OLEDs that emit not only red, orange, green and blue colors, but also function as white emitters, which can really have an impact on reducing the energy consumption. The future prospects that could be explored to improve the research in the highly promising field of OLEDs are also discussed.
\end{abstract}

Handling Editor: Pedro Camargo.

Address correspondence to E-mail: dhanya.s@manipal.edu 


\section{GRAPHICAL ABSTRACT}

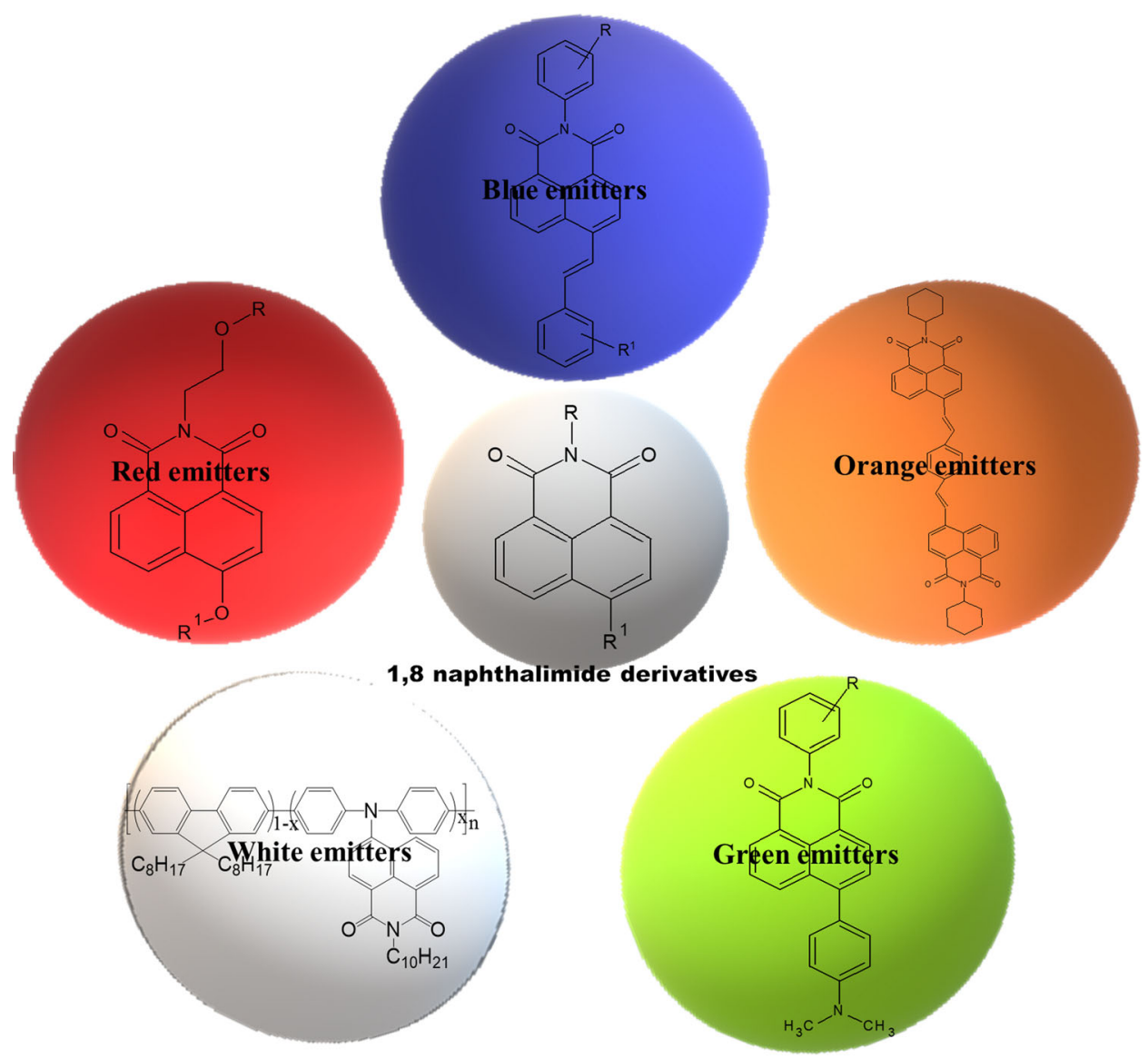

Abbreviations

AIE

$\mathrm{Al}$

$\mathrm{Alq}_{3}$

$\alpha-N P D$

$\mathrm{Ba}$

$\mathrm{BCP}$

$\mathrm{BePP}_{2}$

Bphen

$\mathrm{Ca}$

CBP

CE
Aggregation-induced emission Aluminum

Tris-(8-hydroxyquinoline)aluminum

$N, N^{\prime}$-Bis(naphthalen-1-yl)- $N, N^{\prime}$-bis

(phenyl)-2,2'-dimethylbenzidine

Barium

Bathocuproine

Bis[2-(2-hydroxyphenyl)-pyridine] beryllium

Bathophenanthroline

Calcium

4,4'-N,N'-Dicarbazolylbiphenyl

Current efficiency
CIE

$\mathrm{CuPc}$

D-A

DMAP

EBL

EIL

EL

EML

ETL

EQE

$\mathrm{F}_{4} \mathrm{TCNQ}$

HAT-CN

HBL
Commission international de

l'éclairge

Phthalocyanine copper

Donor-acceptor

4-(Dimethylamino)-phenyl

Electron-blocking layer

Electron injection layer

Electroluminescence

Emissive layer

Electron transport layer

External quantum efficiency

2,3,5,6-Tetrafluoro-7,7,8,8

tetracyanoquinodimethane

2,3,6,7,10,11-Hexacyano-1,4,5,8,9,12-

hexaazatriphenylene

Hole-blocking layer 


\begin{tabular}{|c|c|}
\hline HIL & Hole injection layer \\
\hline HTL & Hole transport layer \\
\hline $\mathrm{HOMO}$ & Highest occupied molecular orbital \\
\hline ICT & Intramolecular charge transfer \\
\hline $\operatorname{Ir}(\text { piq })_{2}($ acac $)$ & $\begin{array}{l}\text { Bis(1-phenylisoquinoline) } \\
\text { (acetylacetonate)iridium(III) }\end{array}$ \\
\hline $\operatorname{Ir}(p p y)_{3}$ & $\begin{array}{l}\text { Tris }[2-\text { phenylpyridinato- } \mathrm{C} 2, \mathrm{~N}] \\
\text { iridium(III) }\end{array}$ \\
\hline ITO & Indium tin oxide \\
\hline $\mathrm{LiF}$ & Lithium fluoride \\
\hline LUMO & Lowest unoccupied molecular orbital \\
\hline $\mathrm{mCP}$ & 1,3-Bis-(N-carbazolyl)benzene \\
\hline o-mCPBI & $\begin{array}{l}9,9^{\prime}-\left(2^{\prime}-(1 H \text { benzo[d]imidazol-1-yl)- }\right. \\
\left.\left[1,1^{\prime} \text {-biphenyl }\right]-3,5-\text { diyl }\right) \text { bis }(9 H- \\
\text { carbazole })\end{array}$ \\
\hline $\mathrm{mCPCN}$ & $\begin{array}{l}\text { 9-(3-(9H-Carbazol-9-yl)phenyl)- } \\
\text { 9H-carbazole-3-carbonitrile }\end{array}$ \\
\hline $\mathrm{MoO}_{3}$ & Molybdenum trioxide \\
\hline $\mathrm{Nf}$ & Nafion \\
\hline NI & 1,8-Naphthalimide \\
\hline NPB & $\begin{array}{l}N, N^{\prime} \text {-Bis(1-naphthyl)- } N, N^{\prime} \text { - } \\
\text { diphenyl-1,1'-biphenyl- } 4,4^{\prime} \text {-diamine }\end{array}$ \\
\hline NTSC & $\begin{array}{l}\text { National Television Standards } \\
\text { Committee }\end{array}$ \\
\hline OLED & Organic light-emitting diode \\
\hline PE & Power efficiency \\
\hline PEDOT & Poly(3,4-ethylenedioxythiophene) \\
\hline PL & Photoluminescence \\
\hline PSS & Polystyrene sulfonate \\
\hline PVK & Poly(vinylcarbazole) \\
\hline $\mathrm{QE}$ & Quantum efficiency \\
\hline QY & Quantum yield \\
\hline RISC & Reverse intersystem crossing \\
\hline RIR & Restriction to intramolecular rotation \\
\hline TADF & $\begin{array}{l}\text { Thermally activated delayed } \\
\text { fluorescence }\end{array}$ \\
\hline TAPC & $\begin{array}{l}\text { 1,1-Bis(4-di-p-tolylaminophenyl) } \\
\text { cyclohexane }\end{array}$ \\
\hline $\mathrm{TcTa}$ & $\begin{array}{l}4,4^{\prime}, 4^{\prime \prime}-\text { Tri }(N- \\
\text { carbazolyl)triphenylamine }\end{array}$ \\
\hline 3ТРYMB & Tris-[3-(3-pyridyl)mesityl]borane \\
\hline TMJ & 1,1,7,7-Tetramethyljulolidin-9-yl \\
\hline TmPyPB & $\begin{array}{l}\left(3,3^{\prime}-\left[5^{\prime}-[3-(3-P y r i d i n y l) \text { phenyl] }\right.\right. \\
{\left[1,1^{\prime}: 3^{\prime}, 1^{\prime \prime} \text {-terphenyl]-3,3' } \text {-diyl] }\right.} \\
\text { bispyridine }\end{array}$ \\
\hline TPBi & $\begin{array}{l}\text { 1,3,5-Tris }(1-\text { phenyl- } 1 H \text {-benzo } \\
\text { [d]imidazol-2-yl)benzene }\end{array}$ \\
\hline TPD & $\begin{array}{l}N, N^{\prime} \text {-Bis(3-methylphenyl)- } N, N^{\prime} \text { - } \\
\text { diphenyl-1,1'-biphenyl-4,4'-diamine }\end{array}$ \\
\hline
\end{tabular}
TSPO1
Diphenyl(4-(triphenylsilyl)phenyl)
TTA
WOLED
phosphine oxide
WPLED
Triplet-triplet annihilation
White organic light-emitting diode
White polymeric light-emitting diode

\section{Introduction}

An organic light-emitting diode (OLED) incorporates a thin film of an organic compound that can produce light as a response to an applied electric current, and this phenomenon is termed as electroluminescence (EL). OLEDs are bestowed with key beneficial characteristics such as bright solid-state emission with good luminescence efficiencies, realizable color tunability, fast response time, less energy consumption, facile fabrication to flat as well as large flexible displays with low cost and lightweight [1-7]. Hence, they find application in digital display devices including television screens, large flat panel computer displays, surface light sources and also in portable appliances such as personal digital assistants, mobile phones and handheld game consoles [8-11]. In terms of display applications, fluorescent OLEDs are more suitable compared to phosphorescent ones because of faster response rate and lower efficiency roll-off $[4,12,13]$. Ever since the innovative research on organic EL reported by Tang and VanSlyke and the pioneering report by Burroughes et al. on polymer EL, the field of OLEDs has fascinated several researchers and has subsequently led to various developments related to discovery of new organic light emitters and design of several devices using them [14-20].

\section{Construction of an OLED}

The fabrication of a typical single-layer OLED involves the introduction of an organic EL material layer amid anode and cathode, and all of them deposited on a substrate that supports the device [21]. However, multilayer OLEDs that incorporate two or more layers can be fabricated by inserting electron or hole-blocking layers (EBL or HBL) adjacent to the emissive layer (EML) to attain maximum recombination of carriers and thereby enhance the 
device efficiency. Modern devices are mainly designed with a simple bilayer structure that comprises of a substrate, an anode, a conducting layer, an EML, and a cathode [22]. The selection of the anode material is based on certain fundamental qualities such as electrical conductivity, optical transparency, and chemical stability. Indium tin oxide (ITO) is the most frequently used anode owing to its high work function that facilitates the instillation of holes into the highest occupied molecular orbital (HOMO) of the organic layer. Gold and platinum are also rarely used as anodes. The conductive layer is generally poly(3,4-ethylenedioxythiophene) with polystyrene sulfonate (PEDOT:PSS) because its HOMO level lies between the HOMO of other frequently used polymers and the work function of ITO, thereby favoring decreased energy barriers for hole injection. Interestingly, the delocalization of $\pi$ electrons in organic molecules with conjugated framework enables them to be electrically conducting because the frontier molecular orbitals (HOMO and lowest unoccupied molecular orbital-LUMO) energy levels of these organic semiconductors are comparable to the valence and conduction bands of the inorganic semiconductors. Thus, these organic materials can function both as conductive and EML of an OLED. The cathodic materials are usually barium $(\mathrm{Ba})$, calcium (Ca) and magnesium (Mg), or their alloys, capped with a protective layer of aluminum (Al) or silver (Ag). These materials display low work functions that can support in electron injection into the LUMO level of the organic layer. The conducting or hole transport layer (HTL) transfers holes from the anode, whereas the EML or electron transport layer (ETL) transports electrons from the cathode. When a DC bias is applied to the electrodes, the recombination of these electrons and holes occurs in the organic layer, emitting light. The color of the light relies on the characteristics of the emissive material, whereas the brightness depends on the applied electrical current [23-27].

\section{Organic materials for LED fabrication}

The main technical features of an OLED include energy and current efficiency (CE), quantum efficiency $(\mathrm{QE})$ of the emitter, operating and inclusion voltage, angle of view, brightness, contrast, life time and temperature range. Nevertheless, the main hurdle while using organic materials in LEDs for fullcolor display is their efficiency, lifetime, stability and inability to obtain pure red, green and blue (RGB) primary colors [28-30]. The vital strategy to improve the device efficiency is to balance the transport of charge carriers by introducing an ETL and a HTL to the diode architecture [31-38]. Though many organic compounds that can function as HTL are accessible, only very limited electron-deficient organic materials that unveil good electron-transporting features are known [39-43]. OLEDs based on tris-(8-hydroxyquinoline) aluminum $\left(\mathrm{Alq}_{3}\right)$ as the electron transporter material have been explored widely [32, 44-47]. Besides $\mathrm{Alq}_{3}$, different materials such as carbazole, oxadiazole, triazole and phenanthroline derivatives [48] are also reported as electron transporters as they own high electron affinity. Attention toward new organic materials started growing immensely since the first report published by Pope et al. on EL from a single crystal of anthracene [28, 49-52]. Consequently, immense experimental efforts were dedicated on designing newer functional materials for organic optoelectronics.

Numerous $\pi$-conjugated molecules that display wide range of semiconducting and conducting behavior were developed as light-emitting and/or charge transport materials. The organic molecules that can potentially act as electron-transporting materials should possess sufficiently high electron affinity, greater than $3.0 \mathrm{eV}$ to enable electron injection from the metallic cathode. In recent years, heterocyclic molecules especially those with strongly electron-withdrawing imide units with excellent intramolecular charge transfer (ICT) features have emerged as ETL materials with promising and potential use in the construction of OLEDs [40, 53-55].

\section{1,8-Naphthalimide as an electron- transporting luminescent material}

The two main requirements for an ETL material in an OLED is the presence of an electron-deficient $\pi$-system with good chemical and thermal stability. In recent years, optical, electrochemical and photoelectrical properties of electron-deficient 1,8-naphthalimide (NI) derivatives with planar rigid architecture [56] have gained increasing attention of researchers, who explore material features. NI derivatives have 


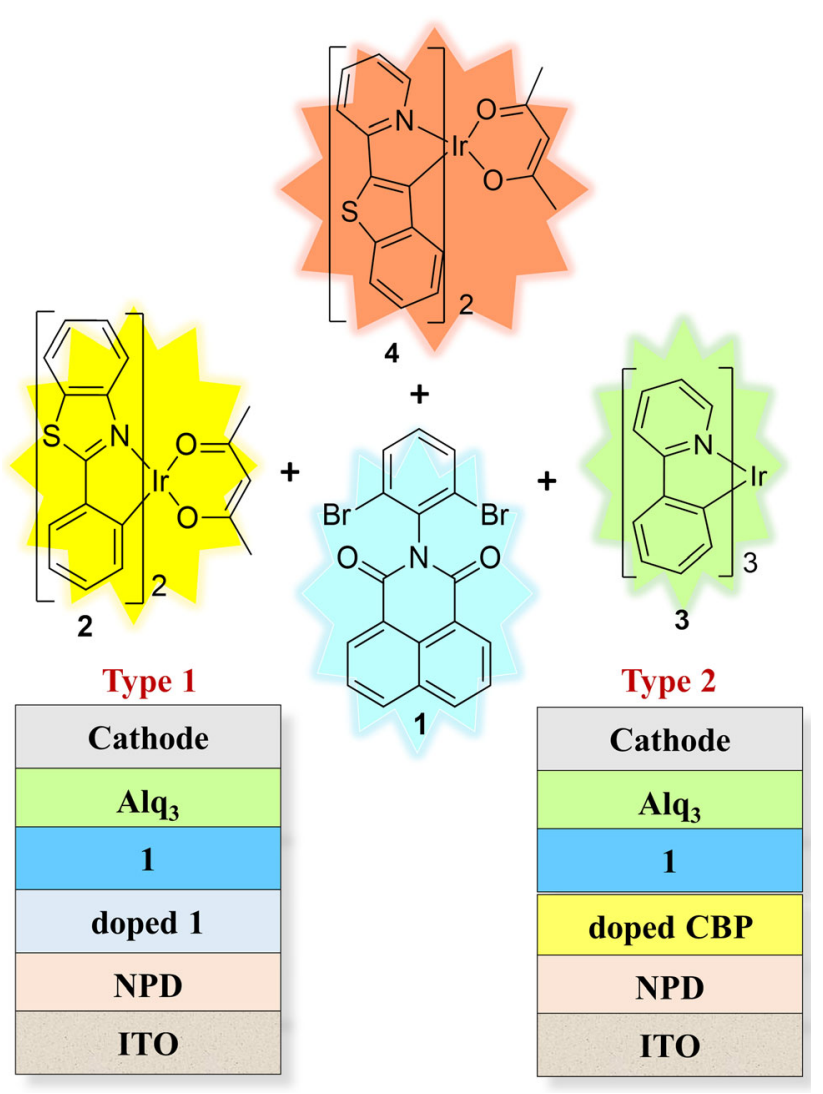

Figure 1 Blue-emitting NI derivatives with Ir-based phosphorescent dopants and their device architectures [48].

been utilized in different applications including laser active media, fluorescence switchers, fluorescent markers in biology, photoinduced electron transfer sensors, ion probes $[57,58]$, etc. Attractive derivatives can be created from NI skeleton, which can display strong fluorescent emission on irradiation, and their rich photophysical properties enable them to function as prime molecular entities for use in optoelectronic devices [59, 60]. The presence of electron-deficient center in NI derivatives generally permit them to achieve high electron affinity, which validates their usage as HBL in OLEDs [61, 62]. These molecules can have low reduction potentials $[48,63,64]$ and wide energy gaps [65-67], and hence are profoundly studied as electron-deficient n-type organic semiconductors [68, 69]. Relatively greater electron affinity, superior charge transfer property, higher glass transition temperature, better film-forming capability, high fluorescence quantum yield (QY), desired chemical and photo-stability, and highly tunable fluorescence emission of NI derivatives demonstrate their possible use as emissive ETL to improve the lifetime and stability of not only small molecules, but also polymer-based OLEDs [29, 68, 70-79].

Since the OLED working is based on the holeelectron recombination in the EML, the color emitted by a NI-based device depends primarily on the electronic features of the material [4, 80-83]. Moreover, the variations in the chemical, photophysical and excited-state optical behavior of NIs are extremely sensitive to the nature and position of the substituents in the aromatic system [66, 84-86]. Thus, NI derivatives with desired features can be synthesized by the reaction of suitable amines with appropriate 1,8-naphthalic anhydrides, which enable to achieve various functionalized derivatives of imide nitrogen and substituted NI skeleton. Extending the aromatic ring system by creating aromatic- or heteroaromaticfused derivatives can be another successful strategy to control the NI properties. The substitution using halo, nitro or amino groups mainly at C3 or C4 position of NI unit permits the introduction of further functional/pendant groups or allows extension of the existing substituent chain length. Moreover, the existence of electron-donating amino and alkoxy moieties at the 3, 4, 5 or 6-position in the aromatic rings of NI framework can not only enhance the fluorescence QY as they trigger a polar charge transfer excited state, but also can shift the absorption to visible region. Their emissions can be extensively and finely tweaked to produce blue to green or yellow fluorescence with a marked Stokes shift. Further, alteration in the nature of the ring or imide nitrogen substituent can direct the fluorescence emission further bathochromically toward red too. In some cases, these NI derivatives can be used as dopants to trap charges between the layers to facilitate luminescence at the host material [48].

NI derivatives are thus good electron-transporting emitters with high electron affinity of about $3.1 \mathrm{eV}$ and electron mobilities as high as $0.16 \mathrm{~cm}^{2} /(\mathrm{Vs})$ [87] that can be custom-modified specifically for an OLED to realize full-color emission having superior performance characteristics such as high fluorescence QY and good photo-stability [88]. Development of OLEDs that emit R/G/B (red/green/blue)-colored fluorescence with appropriate chromaticity and high efficiency are extremely imperative for full-color display applications [8, 89-91]. In this context, construction of large number of NI derivatives that have been investigated to achieve wide color-range is reported by various pioneers. Moreover, as white 
light-emitting OLEDs (WOLEDs) have created substantial performance advances to the general lighting [92-95], attributed to their significant environmental and energy saving benefits, few reports on NI grafted polymers for WOLED applications are also documented. The following sections illustrate the fabrication of OLEDs using different NI derivatives as ETL, in view of achieving optimum optical, electrochemical and thermal properties.

\section{Red-green-blue (RGB) emitters}

Organic frameworks that can offer full-color RGB displays are of high prospective demand. Maximum driving efficacy can be accomplished by means of self-emitting RGB pixels, and hence development of materials that can emit light in each of these primary colors is of crucial importance. NI derivatives have been established to be highly capable and color tunable emitters due to their plausible synthetic modification possibility at the $\mathrm{C} 4$ and the anhydride $\mathrm{O}$ positions. The attachment of diverse aliphatic systems and in particular aromatic skeletons can spread out the conjugation in these molecules to achieve desired features.

\section{Blue emitters}

Blue emitters possess higher electron injection barrier. Hence the major challenge in developing an efficient blue-emitting material relies on the wide optical band gap required to accomplish relatively high-energy emission. NI that exhibit high electron affinity and electron-transporting or hole-blocking features perform as excellent materials suitable for balanced carrier injection in blue OLEDs [68]. The introduction of various electron-donating substituents to NI framework can readily tune their emission color to pure blue.

Phosphorescent OLEDs were fabricated by Kolosov et al. by utilizing four violet-blue-emissive materials such as NI, N-phenyl-NI, N-2,6-dibromophenyl-NI (1), and bis- $N, N-N I$ as EMLs (Fig. 1) [48]. The compound 1 prepared by treating 1,8naphthalic anhydride with 2,6-dibromo aniline showed good charge transport property as holeblocking and electron-conducting material, and also exhibited film-forming property with glossy appearance when doped with phosphorescent complexes. Two sets of OLEDs were designed: type 1 with 1 as a doped luminescent layer and undoped $\mathbf{1}$ as HBL; and type 2 device with doped CBP $\left(1,4-N, N^{\prime}\right.$-dicarbazolylbiphenyl) as luminescent layer and $\mathbf{1}$ as HBL. In both the device types, organometallic iridium (Ir) complexes 2, 3, and 4 that emit yellow, green and red colors, respectively, were used as dopants. The hole hopping between the dopant molecules of positive charge carriers in Ir dye-doped NI films enabled recombination of electrons and holes at the phosphorescent dye. OLED with 4 as dopant showed better performance with dopant emission having lowest energy excited state as the dominant relaxation pathway. The type 2 device with 2 showed voltage-dependent red emission at low bias (4-8 V) and green emission when the bias was increased.

Ulla et al. synthesized twelve molecules $5 \mathbf{a}-\mathbf{f}$ and 6a-f by introducing different halogens, aldehyde and nitrile carrying phenoxy groups at the 4 th position of NI unit to modify the electronic and optical features, including the fluorescence QY (Fig. 2a). NIs 5a-g were prepared from acenaphthene through a series of reactions- bromination, oxidation, imidation with ethanolamine, and final treatment with substituted phenols. On further acetylation, NIs 6a-f were obtained. These derivatives exhibited deep blue fluorescence in thin film state with excellent chromaticity and high stoke shifts [62, 96]. The compounds were stable up to $260-280{ }^{\circ} \mathrm{C}$ and displayed quite higher electron affinities ranging from 3.31 to $3.43 \mathrm{eV}$, compared to the frequently used ETL materials. Electrochemical band gaps were in 2.84-3.02 eV range and the low-lying frontier molecular orbital (FMO) energy levels endowed them with n-type and hole-blocking properties. Intensely blue emissive 5a that crystallized in triclinic space group P-1 was employed as an emissive ETL material in the un-optimized trilayer device, and subsequently as ETL alone in the bilayer device. The devices consisted of ITO as the transparent anode, $\left(4,4^{\prime}\right.$-bis[N-(1naphthyl)-N-phenyl-lamino]-biphenyl ( $\alpha-\mathrm{NPD})$ with high HOMO level as HTL, bathocuproine (BCP) as HBL because it confines the reductant holes that did not recombine with the electrons in the emitting zone, $\mathrm{Alq}_{3}$ as ETL, lithium fluoride (LiF) as the electron injection layer (EIL) and $\mathrm{Al}$ as cathode. The phosphorescent device with blue emitting 5a as ETL demonstrated an excellent external quantum efficiency (EQE) of $1.40 \%$ which was comparable to those with $\mathrm{Alq}_{3}$ as the standard ETL and also without any ETL. 


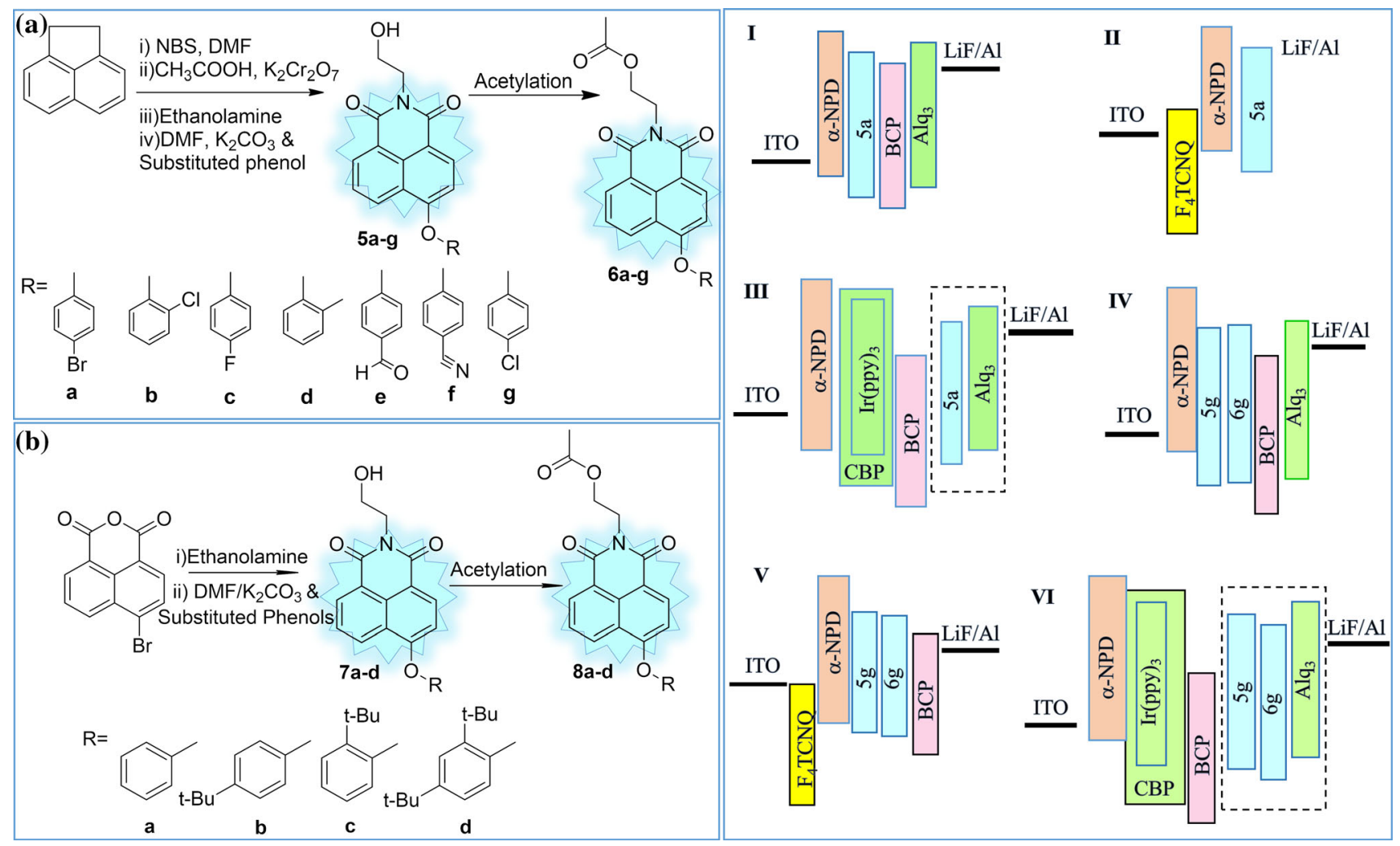

Figure 2 a Blue-emitting NI derivatives and their devices with $5 \mathbf{a}, 5 \mathrm{~g}$ and $\mathbf{6 g}$ as emitters alone, as well as both emitters and ETLs $[62,96,97]$. b NIs carrying phenyloxy or tert-butyl modified

Ulla et al. further in 2017 synthesized two blueemissive chloro-phenoxy NI derivatives $5 \mathrm{~g}$ and $6 \mathrm{~g}$, which possessed high electron affinity, wide band gaps (3.04 and $2.99 \mathrm{eV}$ ) and high stoke shifts for possible use as ETL in OLEDs (Fig. 2a) [97]. They also displayed high molar extinction coefficient due to the charge transfer nature of long wavelength absorption band attributed to the $S_{0} \rightarrow S_{1}$ transitions. HOMO and LUMO levels were quite low making these materials excellent electron-transporting and holeblocking emitters in OLEDs. The phosphorescent devices with NI as ETL exhibited superior performance compared to those without any ETL and similar performance to that of $\mathrm{Alq}_{3}$ devices. 2,3,5,6Tetrafluoro-7,7,8,8 tetracyanoquinodimethane $\left(\mathrm{F}_{4-}\right.$ TCNQ) could efficiently inject the holes from the ITO anode to the HTL in the device.

Wang et al. synthesized eight NIs 7a-d and 8a-d by nucleophilic substitution at $\mathrm{C} 4$ position with either phenyloxy or tert-butyl group attached phenyloxy units and incorporation of $\mathrm{N}$-(2-hydroxyethyl) or $\mathrm{N}$ (2-acetoxyethyl) units at the carboximide sites (Fig. 2) phenyloxy and $N$-(2-hydroxyethyl) or $N$-(2-acetoxyethyl) moieties as substituents [68].

[68]. The compounds $7 \mathrm{c}$ and $8 \mathrm{c}$ with 2-(tertbutyl)phenyloxy group displayed blue fluorescence, good color purity and a QY of 0.29 in their solid films. However, the incorporation of an additional weakly electron-donating (tert-butyl) moiety exhibited greenish blue fluorescence and enhanced the photoluminescence QY to 0.42 owing to the $\mathrm{D}-\pi$-A molecular architecture where D and A denote electron donor and acceptor, respectively. Besides, $\mathbf{8 a}, \mathbf{8 b}$ and $8 \mathrm{c}$ showed higher QY than $7 \mathrm{a}, 7 \mathrm{~b}$ and $7 \mathrm{c}$ due to end capping of acetylated hydroxyl group. Electrochemical and optical band gaps were found to be in the range of $2.95-3.01 \mathrm{eV}$. The compounds were suitable as blue doping materials or non-dopant blue emitters for ETL or HBL owing to high electron affinity values ranging from 3.24 to $3.29 \mathrm{eV}$ and good electron injection abilities.

Pyrene-incorporated NI-based derivatives (9, 10 and 11) were synthesized by Boonnab et al. using palladium-catalyzed cross-coupling reactions, and used to fabricate OLED devices [98]. The 4-bromo1,8-naphthalic anhydride was first alkylated, 


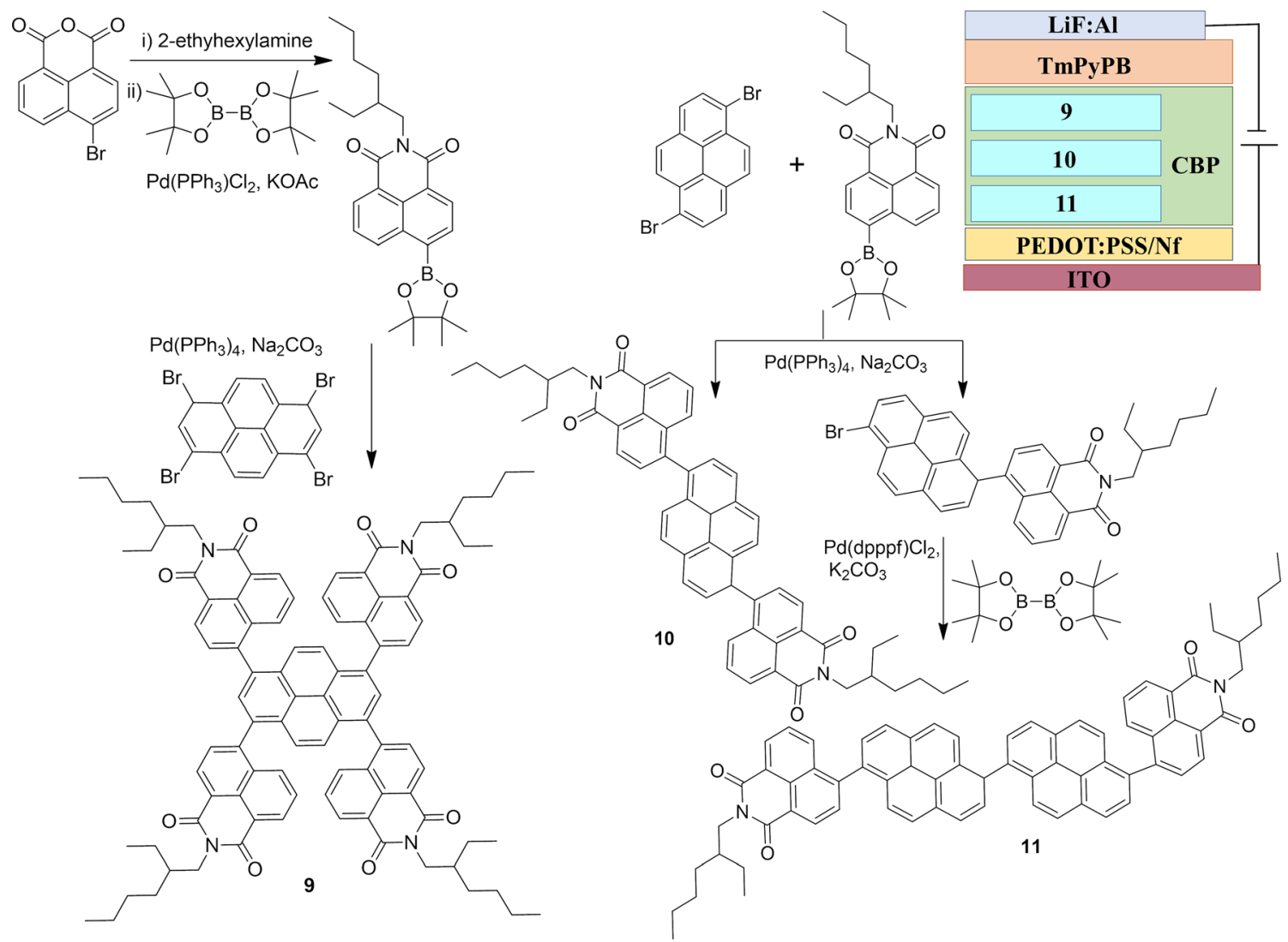

Figure 3 Synthesis of pyrene-incorporated NI-based derivatives and their blue-green-emitting device architecture [98].

converted to the corresponding boronic acid pinacol ester by borylation with bis(pinacolato)diboron catalyzed by $\mathrm{Pd}\left(\mathrm{PPh}_{3}\right) \mathrm{Cl}_{2} / \mathrm{KOAc}$ and then treated with 1,3,6,8-tetrabromopyrene to yield $\mathbf{9 ,} 10$ and $\mathbf{1 1}$ (Fig. 3). These molecules, which exhibited ICT were thermally stable up to $347-447{ }^{\circ} \mathrm{C}$ with $5 \%$ weight loss. Solution processed devices were prepared with configuration: ITO I PEDOT:PSS-Nafion

(Nf) | 9/10/11:10\% CBP I TmPyPb | LiF:Al. The device with CBP-doped 11 as emitter showed better performance with a maximum luminance of $3389 \mathrm{cdm}^{-2}$, a maximum EQE of $3.98 \%$, luminance efficiency of $3.22 \mathrm{cdA}^{-1}$, and a turn-on voltage of $3.2 \mathrm{~V}$. The better performance of $\mathbf{1 1}$ was due to the push-pull mechanism, suitable HOMO and LUMO levels and better charge mobility, which ensured a more balanced and improved recharge recombination behavior within the device.

The reported blue-emitting NI frameworks predominantly carry a substituted phenyloxy group at the C4 position and hydroxyethyl or acetoxyethyl substituents at the nitrogen atom of the electron-deficient NI skeleton. The current efficiencies (CEs) of devices with NI derivatives as electron transport materials are higher compared to the CEs of the devices with NI as EML indicating the charge transfer property of these compounds. Except for $\mathbf{5 g}$ and 6g (VI), EQE and maximum luminescence was better for devices with NI derivatives as ETL rather than EML with the turn-on voltage ranging from 3 to $9.4 \mathrm{~V}$. Device 11 with pyrene-NI-based molecule exhibited maximum EQE of $3.98 \%$ among other reported blue emitters. Over the years, though the improvement in device efficiency was in research focus, the efficiency reported till date for blue OLED is less compared to other categories, and these NI derivatives have high energy gap leading to joule heating and defects in the device [99].

\section{Green emitters}

Besides blue and red emissions, further manipulation of the electron-accepting NI framework has enabled construction of high-performance green and yellow EL materials with ICT characteristics as featured in this section. Novel triphenylamino NI derivatives 


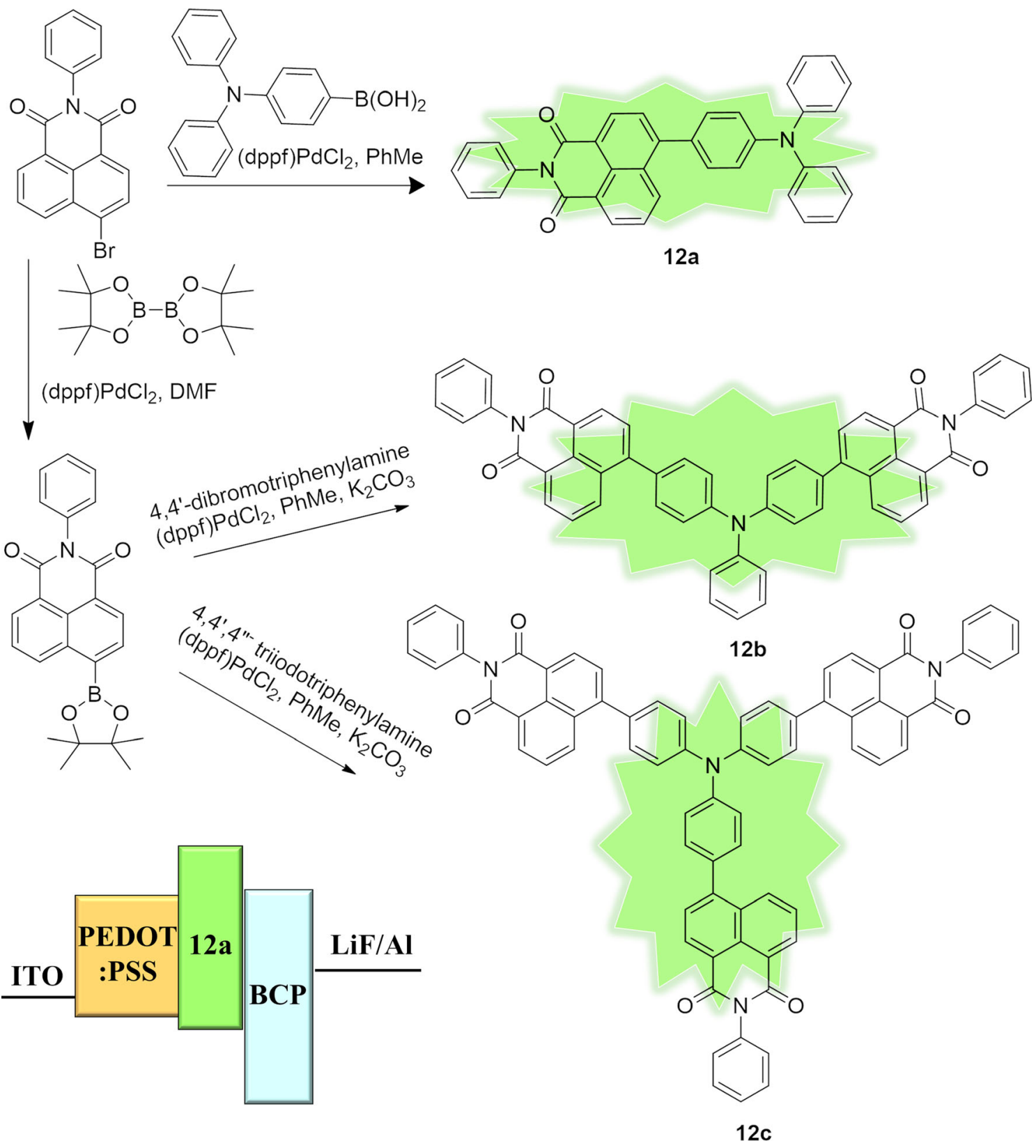

Figure 4 Green-emitting NI derivatives with triphenylamine [80].

12a-c were synthesized via Suzuki cross-coupling using N-phenyl-NI and triphenylamine having distinct photophysical properties by Arunchai et al. (Fig. 4) [80]. The enhanced conjugation, the packing pattern and restricted molecular vibrations in thin film state displayed a blue-shifted emission compared to solution state. These molecules were thermally stable till $350{ }^{\circ} \mathrm{C}$ with an electrochemical band gap in the range of $2.48-2.54 \mathrm{eV}$. A single-layer device with 12a exhibited low performance due to poor film-forming ability and electron migration barrier at the $\mathrm{EML}$ and $\mathrm{LiF} \mid \mathrm{Al}$ electrode interface. BCP was incorporated to improve maximum luminance, and an EL device was fabricated with device structure- ITO | PEDOT:PSS | 12a:CBP | BCP | LiF $\mid \mathrm{Al}$, which exhibited a stable yellowish green fluorescence with CIE coordinates at $(0.295,0.600)$. The device displayed a maximum brightness of $10,404 \mathrm{~cd} / \mathrm{m}^{2}$ at an applied voltage of $19 \mathrm{~V}$, turn-on voltage of $5.8 \mathrm{~V}$, luminance efficiency of $3.77 \mathrm{~cd} / \mathrm{A}$, current density of $410 \mathrm{~mA} / \mathrm{m}^{2}$, and $\mathrm{EQE}$ of $1.11 \%$ due to the efficient energy transfer from host $\mathrm{BCP}$ to $\mathbf{1 2 a}$. The devices 
Figure 5 Green-emitting NI derivatives with a electrontransporting benzazole [29] and $\mathbf{b}$ fluorene units [100] as dopants, and their device structures.
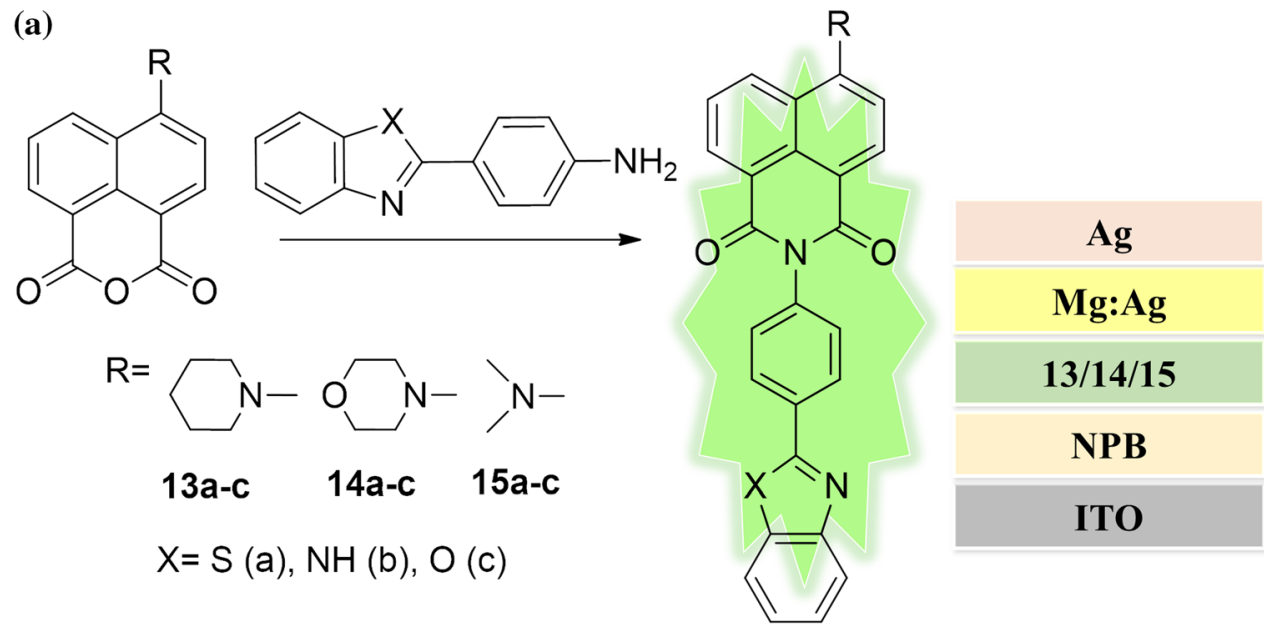

13/14/15a-c

(b)

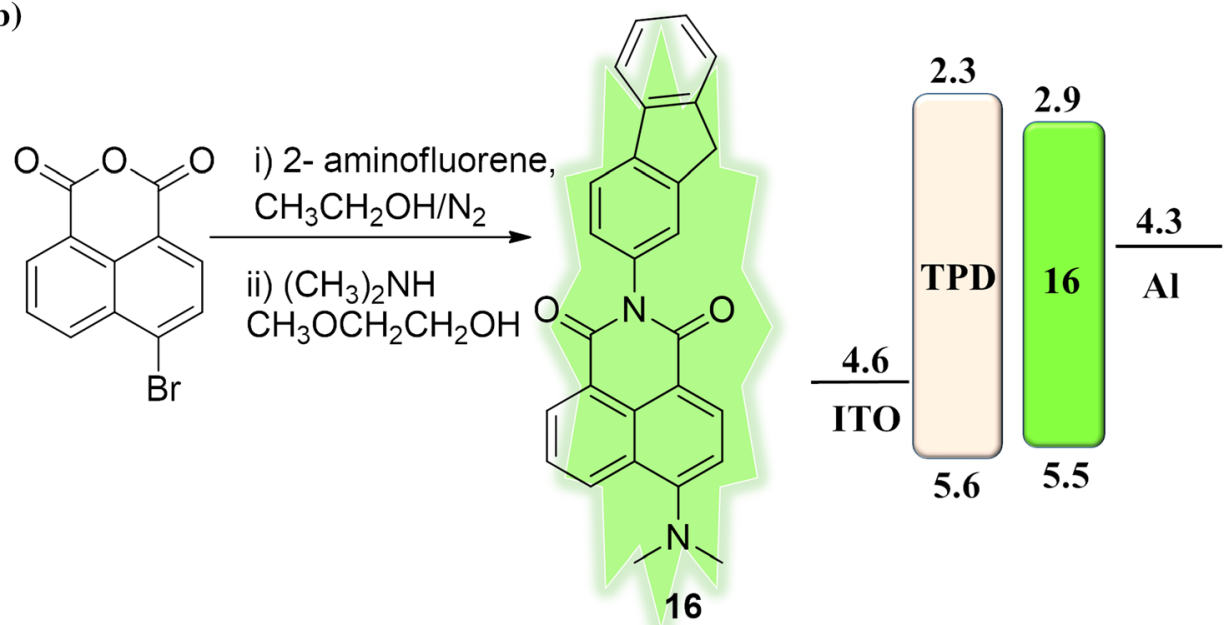

with $12 b$ and 12c showed lower performance due to solubility issues during the spin-casting process.

Ding et al. synthesized nine amorphous NIs (13-15)a-c incorporating electron-transporting benzazole units through direct imidation of NI (Fig. 5a) [29]. The twisted molecular conformation of these molecules hindered their tendency to recrystallize, favoring stable amorphous phase, without altering the extent of conjugation as well as the emission color of the original chromophore. The QE of 13a-c with benzothiazole units was superior to 14a-c and 15a-c bearing benzoxazole and benzimidazole units, correspondingly. The electrochemical $\mathrm{HOMO}$ and LUMO levels were in -5.51 to $-5.68 \mathrm{eV}$ and -2.61 to $-3.26 \mathrm{eV}$ ranges, correspondingly. Green or yellowish green luminescence was observed with the device architecture ITO $\mid \mathrm{NPB}$ (75 nm)|EML $(65 \mathrm{~nm})|\mathrm{Mg}: \mathrm{Ag}| \mathrm{Ag}(100 \mathrm{~nm})$ with 13a, 14b and 15a as EML and ETL. Device with 15a showed better performance with a maximum brightness of $4500 \mathrm{~cd} /$ $\mathrm{m}^{2}$ (at $19 \mathrm{~V}$ ) and a turn-on voltage of $10 \mathrm{~V}$ with CIE coordinates $(0.43,0.53)$ at $556 \mathrm{~nm}$.

A NI derivative with fluorene was synthesized by treating 4-bromo naphthalic anhydride with 2-aminofluorene followed by reaction with dimethylamine (16) by Wang et al. to design a green EL device (Fig. 5b) [100]. The highly luminescent and environmental sensitive molecule $\mathbf{1 6}$ displayed excited-state charge transfer features with good electron affinity, and temperature-independent fluorescence. The derivative possessed an electrochemical band gap of $2.6 \mathrm{eV}$, and low-lying LUMO levels enabled its electron-transporting capability. The device with configuration ITO $|\mathrm{TPD}| \mathbf{1 6} \mid \mathrm{Al}$ exhibited yellowish green EL with a brightness of $3563 \mathrm{~cd} / \mathrm{m}^{2}$ at $19 \mathrm{~V}$, EQE of $0.2 \%$ and luminous efficiency of $0.55 \mathrm{~lm} / \mathrm{W}$. 


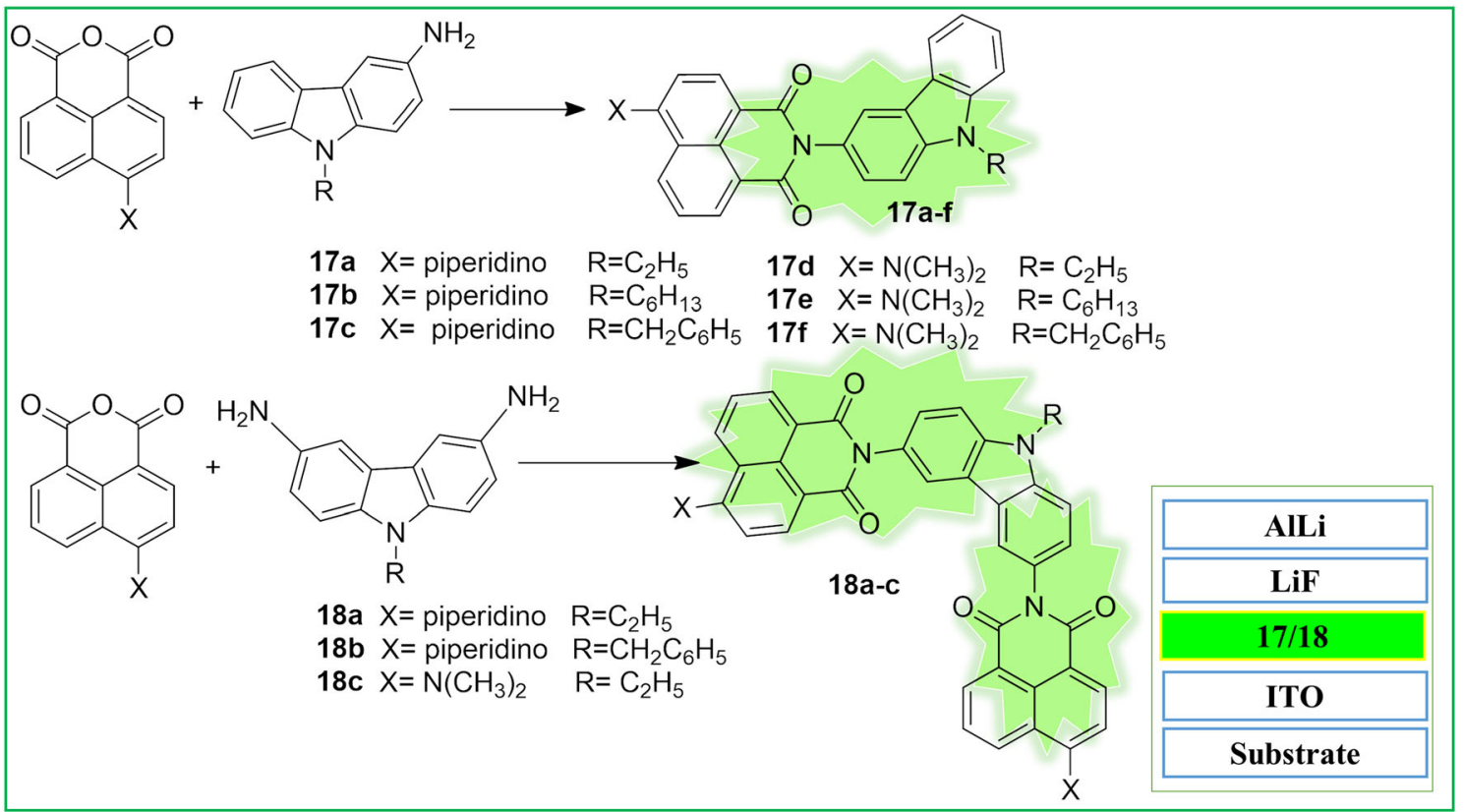

Figure 6 Green NI emitters with carbazole moiety acting as hole transport unit and device structure [101].

Bipolar light-emitting materials possess both electron affinitive and hole-transporting elements for improving the charge injection/transport ability [101]. NI owns good thermal stability due to the presence of imide linkage and high electron affinity owing to the existence of carbonyl moiety, thus favoring stable anion radical formation. Twisted bipolar NI derivatives with carbazole dyads (17a-f) and triads (18a-c) were synthesized through the imidation reaction of substituted naphthalic anhydride by $\mathrm{Zhu}$ et al. (Fig. 6) [101]. The prepared derivatives act as carrier-transporting fragments that could improve charge carrier balance and control the current flow to enhance the internal QE. Stable amorphous phase was favored in these molecules due to aliphatic side chain that can reduce the tendency of recrystallization. Neither the conjugation degree, nor the original emitting chromophore color changed, when the molecular assembly incorporated the hole-transporting moiety into the emitting element. The singlet-singlet energy transfers in these sterically hindered dyads and triads were possible owing to overlap between NI unit absorption and carbazole moiety emission. These thermally stable bipolar emitters with high glass transition temperatures produced stable anion and cation radicals for exciton recombination, and enhanced the stability and lifetime of the fabricated device. Single- layer EL device with these derivatives avoided the layer-to-layer exciton quenching and micro-cavity effect. Single and multiple layered devices having the configuration ITO $|\mathbf{1 7} \mathbf{a}-\mathbf{f} / \mathbf{1 8 a}-\mathrm{c} \quad(50-100 \mathrm{~nm})| \mathrm{LiF}$ $(1 \mathrm{~nm}) \mid \mathrm{AlLi}$ and ITO $|\mathrm{CuPc} \quad(10 \mathrm{~nm})| \mathrm{TPD}$ $(10 \mathrm{~nm})|\mathbf{1 7 a}-\mathbf{f} / \mathbf{1 8 a}-\mathrm{c} \quad(30 \mathrm{~nm})| \mathrm{BePP}_{2} \quad(45 \mathrm{~nm}) \mid \mathrm{LiF}$ $(1 \mathrm{~nm}) \mid$ AlLi, respectively were fabricated. The device with compound $\mathbf{1 8 b}$ displayed maximum brightness of $260 \mathrm{~cd} / \mathrm{m}^{2}$ at a driving voltage of $18 \mathrm{~V}$. Bis[2-(2-hydroxyphenyl)-pyridine] beryllium (BePP2) served as the ETL, whereas phthalocyanine copper $(\mathrm{CuPc})$ and TPD acted as the HTL to improve the device efficiency. Greenish yellow emission was purely from NI moiety, whereas the carbazole component did not contribute to the light emission, instead facilitated the electron-blocking and hole injection. Thus, these bipolar dyad emitters generated stable anion and cation radicals for the recombination of holes and electrons to produce excitons that undergo radiative decay in the NI moiety, resulting in its characteristic emission.

Zagranyarski et al. reported 3,4-dioxin annulated NIs 19-23 possessing six-membered rings with two oxygen atoms fused at positions 3 and 4 prepared through reaction of $\mathrm{N}$-substituted 3,4,6-tribromo NI with catachol and 2-3 dihydroxy naphthlene, and subsequent Suzuki coupling (Fig. 7) [102]. The different substituents at $6^{\text {th }}$ position combined with the 


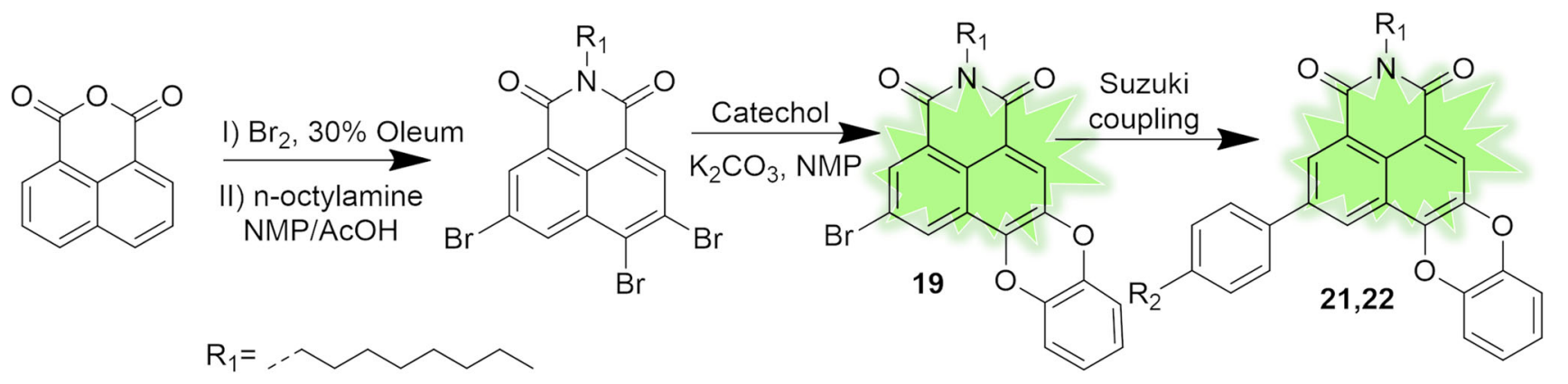

20: $\mathrm{R}_{2}=\mathrm{H}$

21, 22: $\mathrm{R}_{2}=-$ -
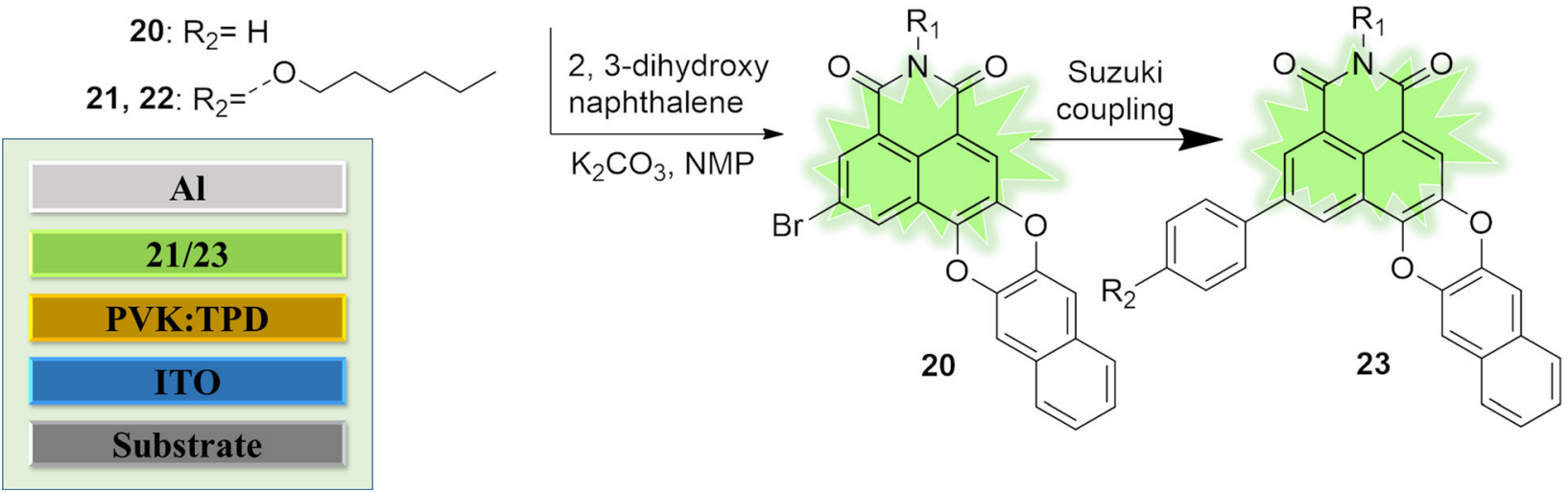

Figure 7 Green NI emitters with 3,4-dioxin annulated structural framework and device architecture [102]

size of aryl-dioxin moiety influenced the emission characteristics of the derivatives. The FMO energy levels and the band gaps increased with the incorporation of a hexyloxy group and a second benzene ring in the dioxin moiety and showed a more pronounced effect with the aromatic ring extension. Among the two NIs $\mathbf{2 1}$ and $\mathbf{2 3}$ that were functionally tested as EL materials in device with ITO | PVK:TPD | 21/23 | Al architecture, better device performance with cyan-greenish emission was obtained with 21 as the EML because of the specific orientation of aliphatic chains toward the conjugated aromatic systems. A working OLED with NI 22 as EL could not be implemented as the long alkoxy group hindered the electron-hole recombination process.

The NI derivatives reported for green OLEDs usually have electron-deficient imine nitrogen and the 3rd or 4th position of NI backbone substituted with various moieties such as phenyl, long-chain aliphatic group, carbazole and fluorene. Most of these green-emitting NI derivatives were used as undoped emitters, except the single-layer device with $\mathbf{1 2}$ that exhibited poor efficiency. Hence, it was not only doped with CBP, but also BCP layer was added to improve the device efficiency. Maximum luminescence was observed when CBP was doped with $\mathbf{1 2}$ which is sixfold higher than other reported greenemitting NI derivatives for OLEDs.

\section{Orange emitters}

Efficient orange-emitting NI derivatives can be prepared either by shortening the $\pi$-conjugation length or by introducing non-planarity in the molecular conformation. Two divinylenes (24 and 25) that carried fluorene and phenylene units, together with a terminal electron-accepting NI moiety in their structural framework, were synthesized by Mikroyannidis et al. through Heck coupling reaction of 4-bromo- $\mathrm{N}$ cyclohexylnaphthalimide with 9,9-dihexyl-2,7-divinylfluorene and 1,4-bis(dodecyloxy)-2,5-divinylbenzene, respectively (Fig. 8a) [103]. They exhibited greenish orange fluorescence with QY of 0.1 and optical band gap of about $2.5 \mathrm{eV}$. A bilayer device with the architecture ITO | PEDOT:PSS (30 nm)। PVK (25\%) 24/25 doped in PVK $(75 \mathrm{~nm}) \mid \mathrm{TPBi}$ $(25 \mathrm{~nm})|\mathrm{LiF}(0.5 \mathrm{~nm})| \mathrm{Al}(200 \mathrm{~nm})$ was fabricated, wherein poly(vinylcarbazole) (PVK) functioned as both HTL and host light EML, 1,3,5-tris-(1-phenyl-1$H$-benzo[d]imidazole-2-yl)benzene (TPBi) served as both ETL and HBL, and LiF improved the electron injection barrier. The green-orange and orange 
(a)

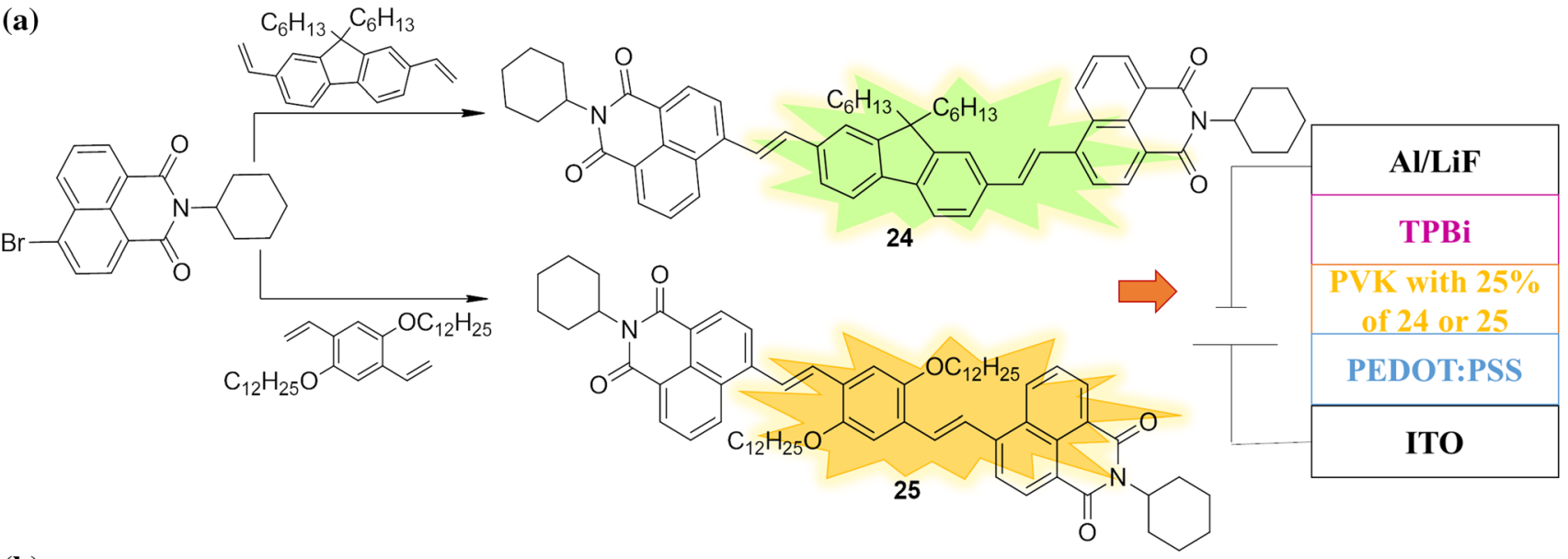

(b)
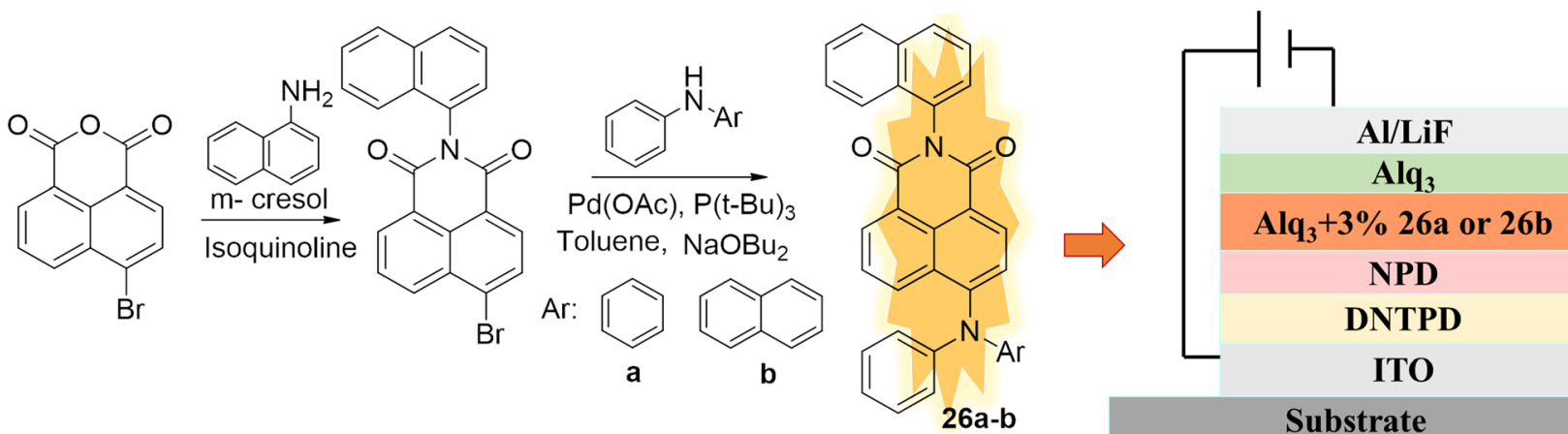

Figure 8 Orange-emitting NI compounds with a divinylene fluorine and phenylene [103], b N-naphthyl substituentes [104].

emissions corresponding to 24 and 25 , respectively, exhibited maximum luminescence efficiency of $0.15-0.10 \mathrm{~cd} / \mathrm{A}$.

Two orange-emitting D-A molecules (26a-b) based on 2-naphthalene-1-yl-benzo[de]isoquinoline-1,3dione as electron-accepting core and arylamine substituents as both hole-transporting and electron-donating groups were prepared through $\mathrm{N}$-arylation by Jung et al. (Fig. 8b) [104]. Electrochemical band gaps of both the molecules were $\sim 2.42 \mathrm{eV}$, and thermal stabilities were found to be $368^{\circ} \mathrm{C}$ and $407^{\circ} \mathrm{C}$ for $26 a$ and 26b, respectively. EL was observed at 574 and $588 \mathrm{~nm}$ with luminance efficiencies of $6.6 \mathrm{~cd} / \mathrm{A}$ at $5.9 \mathrm{~V}$ and $5.9 \mathrm{~cd} / \mathrm{A}$ at $6.3 \mathrm{~V}$ for $\mathbf{2 6 a}$ and $\mathbf{2 6 b}$, correspondingly. These orange emitters were highly efficient because the asymmetric and bulky structure could control the intermolecular dipole-dipole interaction.

Zeng et al. synthesized two red-orange emitters 27 and $\mathbf{2 8}$ with rigid acridine unit as electron donor and NI moiety as acceptor that exhibited thermally activated delayed fluorescence (TADF) and possessed pre-twisted charge transfer state exhibiting EQE up to $30 \%$ [105] (Fig. 9a). The substitution at the acridine moiety can vary their electronic and photophysical properties. High QY, TADF and horizontally oriented emitting dipoles of these two emitters make them suitable EMLs in OLEDs. Horizontal dipole ratios of both the EMLs were higher than the host 9-(3- $(9 \mathrm{H}-$ Carbazol-9-yl)phenyl)-9H-carbazole-3-carbonitrile $(\mathrm{mCPCN})$ and was beneficial in optical outcoupling of OLEDs. Device was fabricated with configurationITO $\left|\mathrm{MoO}_{3}\right| \mathrm{TAPC}|\mathrm{mCP}| \mathrm{mCPCN}: \quad \mathrm{x}$ wt\% 27 or $28|3 T P Y M B| \mathrm{LiF} \mid \mathrm{Al}$. Both the emitters were doped with $\mathrm{mCPCN}$ (1.5 wt $\%$ of 27 and $6 \mathrm{wt} \%$ of 28 ) with an emission at 581-600 $\mathrm{nm}$ at a cut off voltage of $3 \mathrm{~V}$ with EQE of $21-29.2 \%$.

\section{Orange emitters with TADF properties}

TADF can provide remarkably effective emission through singlet and triplet exciton harvesting. The small singlet-triplet energy gaps allow the thermal conversion of triplet excitons to singlet species in TADF emitting materials by reverse intersystem crossing (RISC) to achieve 100\% theoretical internal 
(a)<smiles>[Z7]C1(C)c2ccccc2N(c2ccc3c4c(cccc24)C(=O)N(c2ccc(C(C)(C)C)cc2)C3=O)c2ccccc21</smiles>

27<smiles>C#CC1CCCCC1(c1ccccc1)c1ccccc1N(c1ccc(C(C)(C)C)cc1)c1ccc2c3c(cccc13)C(c1ccccc1)(c1ccccc1)c1ccccc1-2</smiles>

1.8

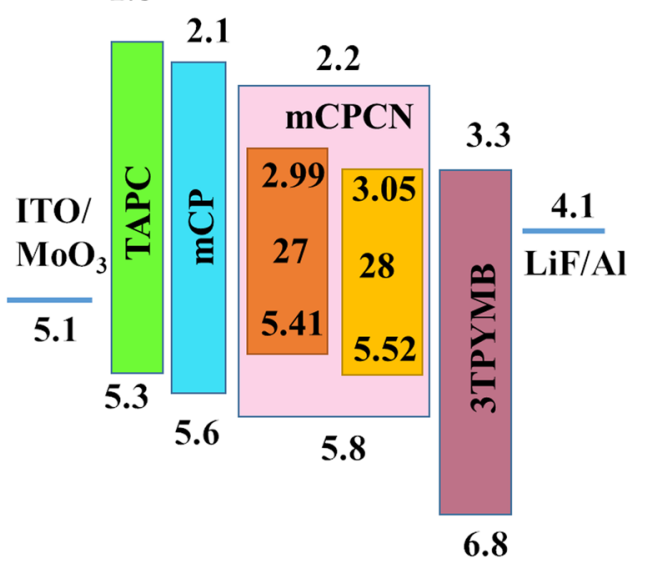

(b)

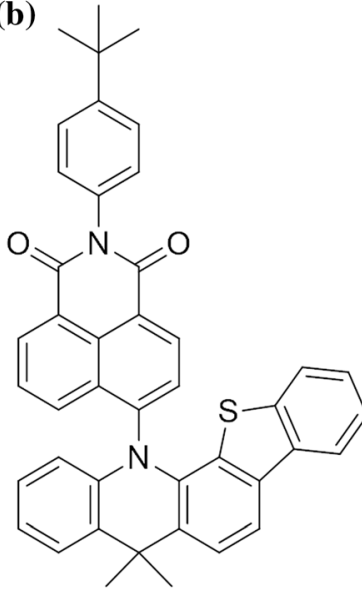

29

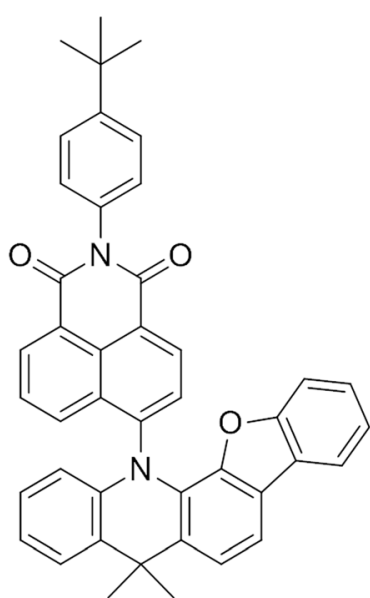

30

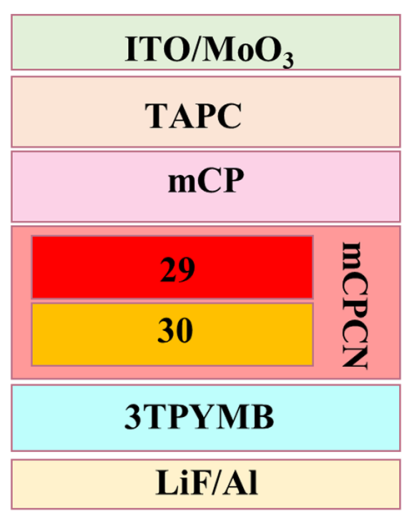

LiF/Al

Figure 9 Orange-emitting NIs with $\mathbf{a}$ acridine units [105] and $\mathbf{b}$ benzofuran and benzothiophene fused to the acridine framework [108] along with their device architecture.

QE of TADF-OLEDs. Recently, emitters with TADF have been reported as alternative for phosphorescent emitters for their utilization of both singlet and triplet excitons and their easily modified metal-free pure organic structures [106, 107]. Though many blue, green and yellow TADF materials are reported, the development of the orange-red TADF emitters remains to be a big challenge.

Chen et al. developed two orange-red TADF active NI emitters (29 and 30) with benzofuran and benzothiophene fused to the acridine framework (Fig. 9b) [108]. These NI derivatives tend to possess plane and crooked form, where crooked form acridine leads to a lower twisting angle between donor and acceptor, thus exhibiting the TADF property.
Broad emission peaks were observed at 600 and $650 \mathrm{~nm}$ for 29 and 30, respectively, and the red shift in the emission maximum of $\mathbf{3 0}$ is attributed to the stronger electron-donating ability of benzothiophenefused acridine unit. Multilayer device was fabricated with the configuration ITO $\left|\mathrm{MoO}_{3}\right|-$ TAPC $|\mathrm{mCP}| \mathrm{mCPCN}: \quad x \quad$ wt $\%$ 29/30:3TPYM$\mathrm{B}|\mathrm{LiF}| \mathrm{Al}$. NI 30-based device exhibited a better EL performance with maximal EQE of $20.3 \%$, CE of $49.2 \mathrm{~cd} \mathrm{~A}^{-1}$, power efficiency (PE) of $51.4 \mathrm{~lm} \mathrm{~W} \mathrm{~m}^{-1}$.

Wang et al. prepared chiral TADF orange-red NIbased emitters 31a-b by lactamizing 4-bromo-1,8naphthalic anhydride with (-)-(R,R)-1,2-diaminocyclohexane or (+)-(S,S)-1,2-diaminocyclohexane and further palladium-catalyzed $\mathrm{C}-\mathrm{N}$ coupling reaction 


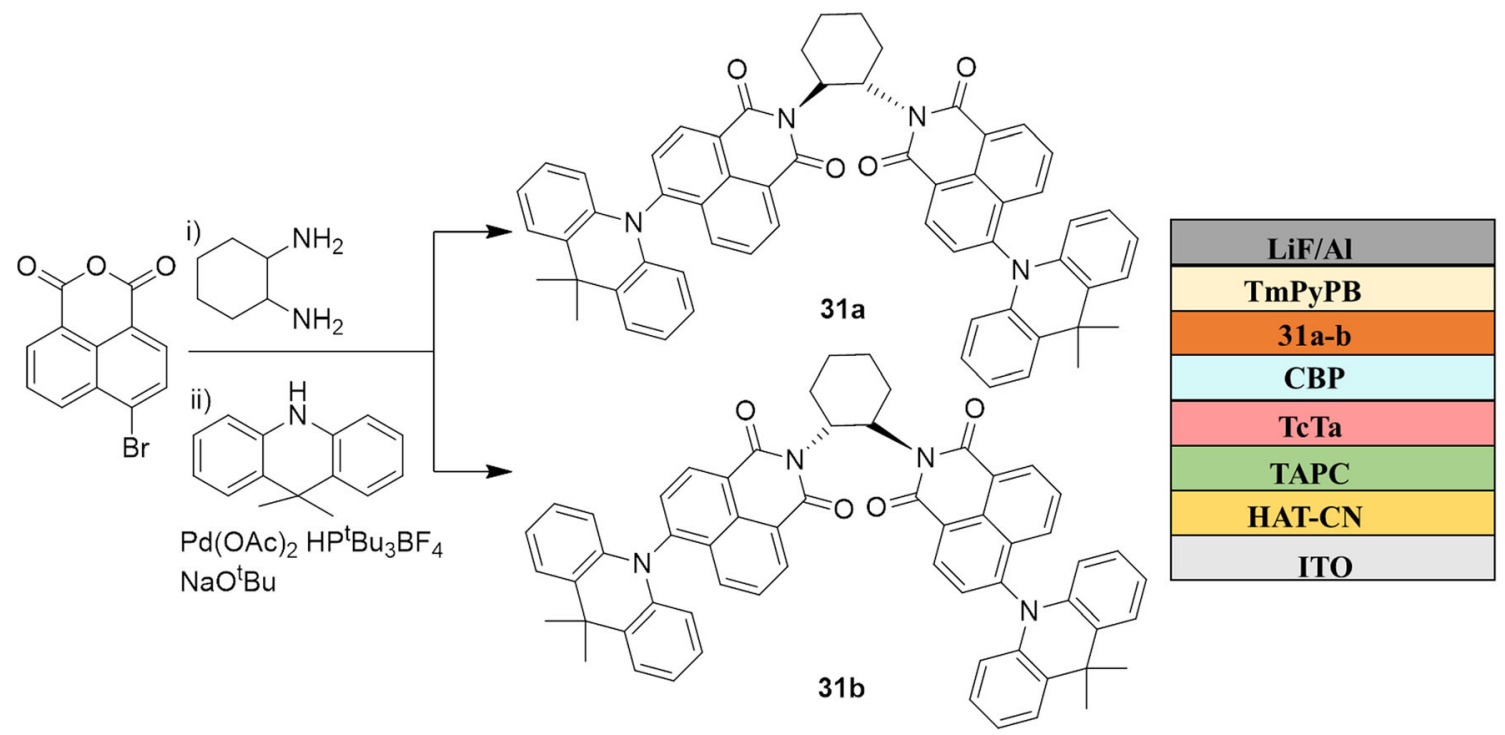

Figure 10 Chiral orange-red TADF emitters and their device architecture [109].

with 9,9-dimethyl-9,10-dihydroacridine (Fig. 10) [109]. These compounds possess higher thermal stability up to $405{ }^{\circ} \mathrm{C}$ with excellent electrochemical properties, good TADF and circularly polarized luminescence properties. Devices were constructed by co-depositing CBP with 6 wt $\%$ of these emitters: ITO | HAT-CN | TAPC | TcTa | CBP | 31a-b | TmPyPB | $\mathrm{LiF} \mid \mathrm{Al}$. The 31b-based device exhibited an orangered emission with a peak at $592 \mathrm{~nm}$ and high maximum EQE of $12.4 \%$, and its maximum $\mathrm{CE}$ and $\mathrm{PE}$ were $28.5 \mathrm{cdA}^{-1}$ and $28.8 \mathrm{lmW}^{-1}$, respectively.

The NI skeleton was appended with a variety of substituents to obtain orange emission, and in all the devices different hosts like $\mathrm{Alq}_{3}, \mathrm{PVK}$ and $\mathrm{mCPCN}$ were used. This category of emitters is considered as the linkage between green and red with mixed emission color and displayed a EQE of 5\%, wherein orange-red TADF emitters showed maximum EQE of $20.3 \%$ with maximum luminescence of $2350 \mathrm{cdm}^{-2}$. D-A type and chiral molecules with orange-red TADF emission displayed improved EQE and maximum luminescence.

\section{Red emitters}

Red electrofluorescent materials are classified into molecules that (1) incorporate polycyclic aromatic hydrocarbon framework and (2) display ICT features with $\mathrm{D}-\pi-\mathrm{A}$ structures. Only a few red emitters with high fluorescent QYs are reported for OLED fabrications till date [110, 111]. Though few europium chelate complexes, pyran and porphyrin derivatives [112-116] are among those investigated as red-emitting materials, they suffer from various disadvantages such as (1) concentration/aggregation caused fluorescence quenching, (2) lack of good chromaticity, (3) lower EQE, (4) complicated synthetic routes, (5) inadequate overlap between the emission bands of the red dopant and the host matrix, (6) low doping levels and (7) high production cost [117-120]. Therefore, developing red emitters with improved color purity and high efficiency still remain a challenge. The rigid $\pi$-conjugated electron-withdrawing NI core skeleton can be manipulated to design longwavelength emitters by introducing electron donors at C4 position in order to achieve deep LUMO levels, bathochromically shifted emission wavelengths and improved fluorescence QY [56, 121, 122].

Azomethine derivatives of 4-amino-N-phenyl-NI, wherein the imine unit acts as a part of the conjugation linker joining the N-phenyl-NI and a phenyl unit, were found to exhibit wide ranges of emission colors. Gan et al. synthesized two series of amorphous Schiff bases 32a-e and 33a-b (Fig. 11) by condensing four hydrazino-NIs with suitable aldehydes [123]. ICT occurred in these derivatives between the electron providing amino substituent and the electron-accepting NI. The extended amino-conjugated system at the imide nitrogen and the increased electron-contributing ability of the moieties attached to 


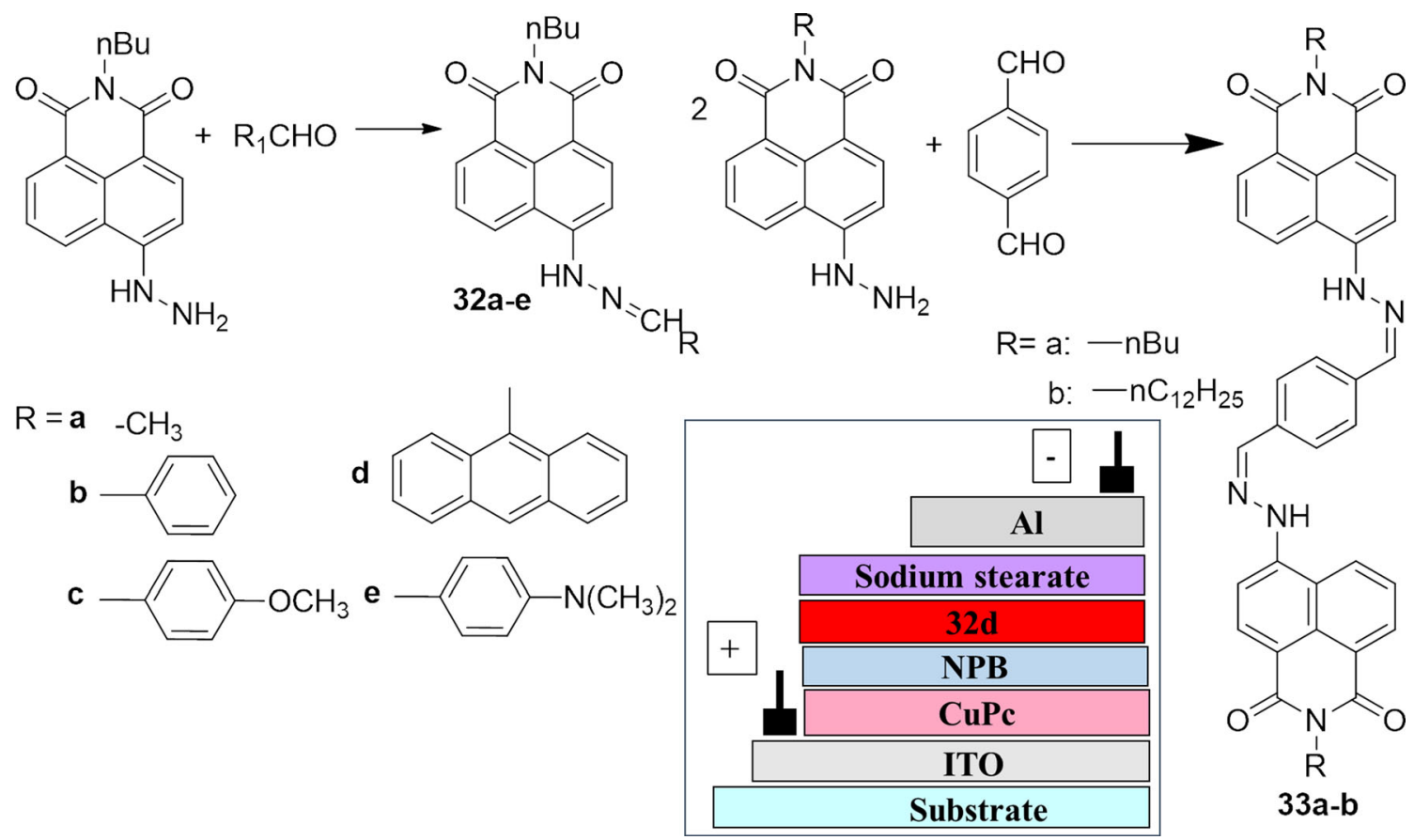

Figure 11 Red-emitting Schiff base-NI derivatives [123] and the device architecture.

NI backbone led to large bathochromic shift in the emission of the Schiff bases in their film form. These red-emitting materials did not exhibit any concentration causing quenching effects, and the fluorescence lifetimes of these emitters were dependent on the electron donor substituents connected through the $\mathrm{C}=\mathrm{N}$ group. The OLED with $\mathbf{3 2 d}$ as the nondoping EML in the device ITOICuPc (12 nm) INPB $(30 \mathrm{~nm})|\mathbf{3 2 d}(45 \mathrm{~nm})|$ sodium stearate $(2 \mathrm{~nm}) \mid \mathrm{Al}$ $(100 \mathrm{~nm})$ showed maximum luminance and current density values of $15.5 \mathrm{~cd} / \mathrm{m}^{2}$ and $2.9 \mathrm{~mA} / \mathrm{cm}^{2}$, respectively, at an applied voltage of $22 \mathrm{~V}$. CuPc served as HTL in the device to maintain the injection balance of electron and hole. The device performance was poor compared to that obtained with red-doping method.

Zhou et al. discovered that ICT featured NI 34 could function as a host material in orange-redemitting OLED through triplet-fusion mediated triplet harvesting (Fig. 12a) [124]. Molecule 34 displayed triplet-fusion delayed fluorescence (TFDF) with lesser exchange energy and lower lying $\pi \pi^{*}$ level than charge transfer state, thereby contributing to triplet harvesting via $P$-type delayed fluorescence, instead of thermally activated E-type one. The electrochemical molecular orbital levels were found to be - 5.64 and $-3.14 \mathrm{eV}$, correspondingly. The device configuration ITO |NPB $(30 \mathrm{~nm})|\mathrm{CBP}(2 \mathrm{~nm})| 34: 35$
(6 $\mathrm{wt} \%, 20 \mathrm{~nm}) \mid$ Bphen $(40 \mathrm{~nm}) \mid \mathrm{Mg}: \mathrm{Ag}$ in which $4,4^{\prime}-N, N^{\prime}$-dicarbazolylbiphenyl (CBP) and bathophenanthroline (Bphen) acted as HBL and ETL materials, respectively, showed maximum $\mathrm{CE}$ of $7.2 \mathrm{~cd} \mathrm{~A}^{-1}$ and brightness of $16,840 \mathrm{~cd} \mathrm{~m}^{-2}$. The triplet-triplet annihilation (TTA) process dominated in devices with these NI derivatives functioning as both the doping matrix and non-doped emitter.

Red-emitting NI derivative 36 that possess pyrene moiety at $\mathrm{C} 4$ position was synthesized by Bezvikonnyi et al. via Suzuki-Miyaura coupling between rac-2ethylhexylamine attached NI derivative and pyrene1-boronic acid (Fig. 12b) [125]. Different devices were prepared using 36 as dopant: $\mathrm{ITO}\left|\mathrm{MoO}_{3}\right|$ $\mathrm{NPB} \mid \operatorname{Ir}$ (piq) $)_{2}$ (acac) $(x \%): 36|\mathrm{TPBi}| \mathrm{LiF} \mid \mathrm{Al}$ where $x$ is $10,15,25 \%$, respectively. These devices emitted red light with CIE coordinates of $(0.677,0.319)$ at applied external voltages in the range $4-10 \mathrm{~V}$. Two nondoped devices with 36 were tried with device configuration: $\mathrm{ITO}\left|\mathrm{MoO}_{3}\right| \mathrm{NPB}|\mathrm{TcTa}| \mathrm{mCP} \mid 36$ | TSPO1 | TPBi $|\mathrm{Ca}| \mathrm{Al}$ and ITO $\left|\mathrm{MoO}_{3}\right|$ mMTDATA $\mid$ $\mathrm{NPB}|\mathrm{mCP}| 36|\mathrm{TSPO} 1| \mathrm{TPBi} \mid \mathrm{Li} \mathrm{Al}$, which emit in blue region. The 36: $\operatorname{Ir}\left(\right.$ piq) ${ }_{2}$ (acac)-based phosphorescent OLEDs demonstrated maximum $\mathrm{CE}, \mathrm{PE}$, and EQE of $10.8 \mathrm{cdA}^{-1}, 7 \mathrm{lmW}^{-1}$, and $13.6 \%$, respectively. Low-efficiency roll-offs of these red devices are attributed to a deactivation by triplet-polaron quenching processes. 
Figure 12 a Host (34) and guest (35) arrangement showing TTA [124] and b synthesis of pyrene-based NI derivative [125] and redemitting device architecture.

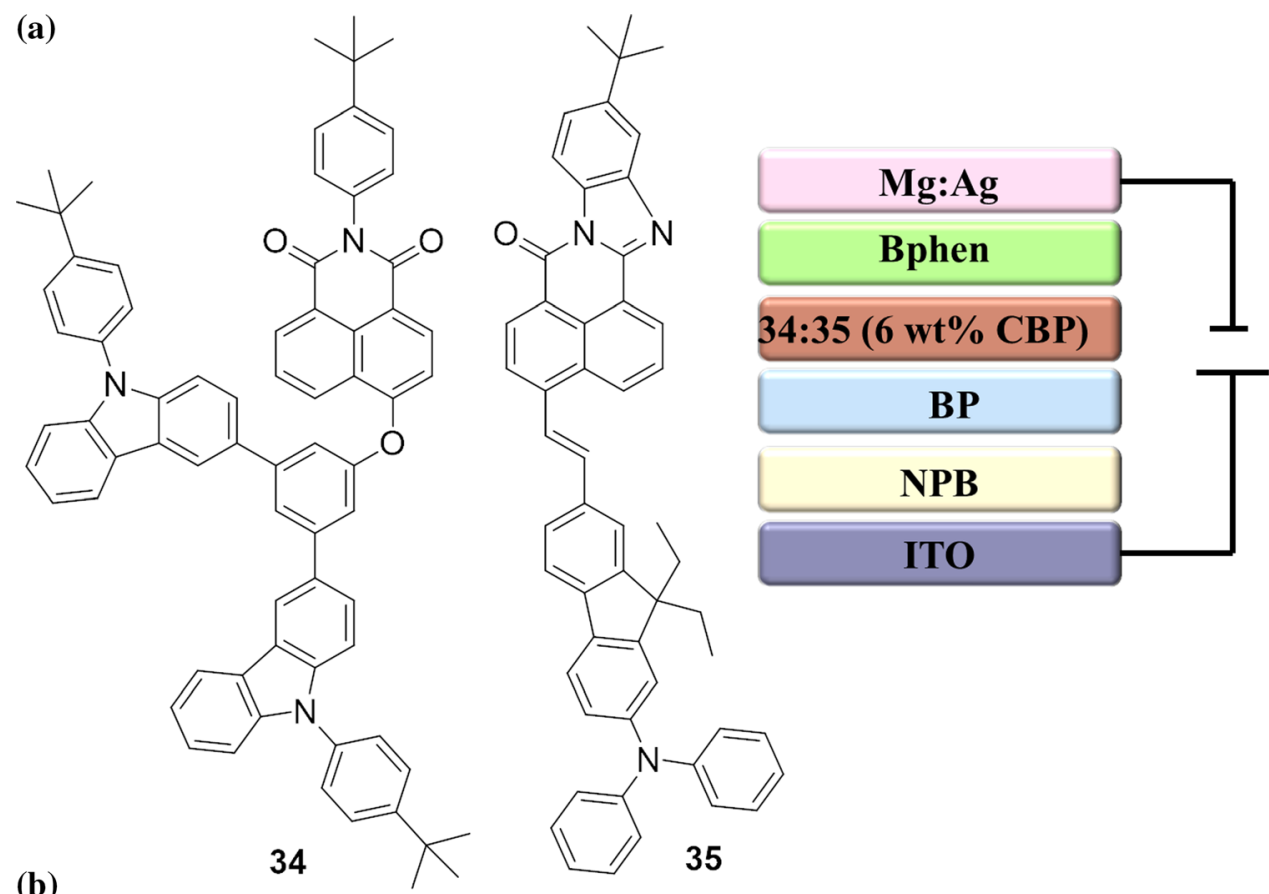

(b)

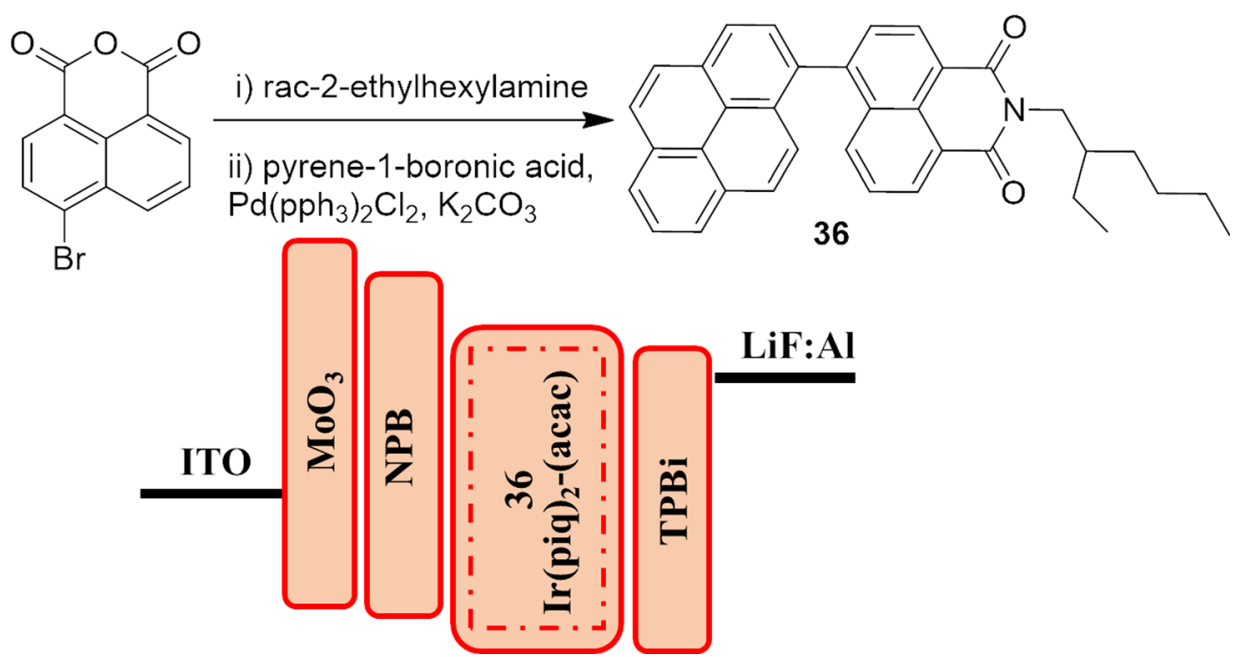

Luo et al. developed three red emitters $37 \mathbf{a}-\mathbf{b}$ and 38 with $\mathrm{D}-\pi$-A structure incorporating 4-(dimethylamino)-phenyl (DMAP) or 1,1,7,7-tetramethyljulolidin-9-yl (TMJ) as electron donors, NI moiety as acceptor and ethene-1,2-diyl as the $\pi$-bridge (Fig. 13a) [117]. The occurrence of highly electron-rich 4-dimethylaminophenyl donor group endowed 37a with a red emission. However, concentration caused quenching was observed in case of $\mathbf{3 7 b}$ due to the alleviated intermolecular interactions when a bulkier 2,6-di(isopropyl)phenyl subunit replaced the n-hexyl chain. Nevertheless, the modification of the 4 -(dimethylamino)phenyl donor of $37 \mathrm{~b}$ with an electron-rich TMJ substituent suppressed concentration quenching and rendered compound 38 with more improved chromaticity. Electrochemical band gaps were 1.94, 1.90 and $1.71 \mathrm{eV}$ for $37 \mathrm{a}, 37 \mathrm{~b}$ and 38, correspondingly. A heavily doped standardred OLED fabricated with $\mathbf{3 8}$ as the guest dopant having structure ITOI $\mathrm{MoO}_{3} \quad(1 \mathrm{~nm}) \mid \mathrm{TcTa}$ $(40 \mathrm{~nm})|34: 38(14 \mathrm{wt} \%)(20 \mathrm{~nm})| \mathrm{TPBi}(45 \mathrm{~nm}) \mid \mathrm{LiF}$ $(1 \mathrm{~nm}) \mid 1(80 \mathrm{~nm})$, wherein TcTA and TPBi serving as HTL and ETL, respectively, exhibited maximum EQE and $\mathrm{CE}$ of $1.8 \%$ and $0.7 \mathrm{cdA}^{-1}$.

Wang et al. designed a red-emitting neutral red-NI derivative 39, which incorporated a bridged double bond in the ring and exhibited ICT property (Fig. 13b) [126]. The derivative 39 was prepared 


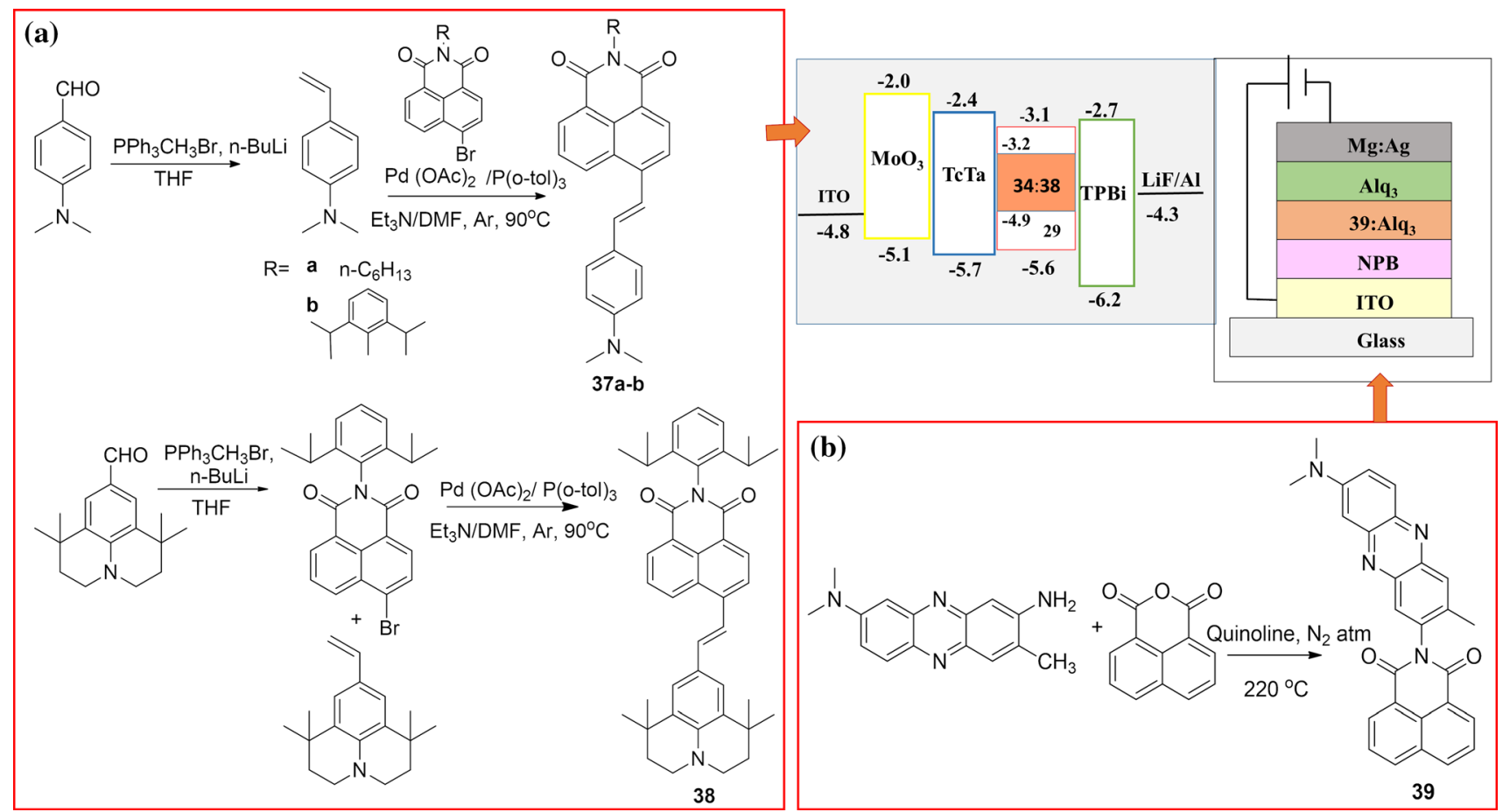

Figure 13 Red-emitting NI compounds and their devices with a D- $\pi$-A structure possessing DMAP or TMJ as electron donors [117] and b ICT active moiety as dopant [126].

through imidation reaction of naphthalic anhydride with neutral red in quinoline. The HOMO and LUMO states were 5.4 and $3.2 \mathrm{eV}$, correspondingly. Highly efficient multilayer EL device was fabricated with $1 \% 39$ as dopant having structure as ITO I NPB $(60 \mathrm{~nm})\left|\mathrm{Alq}_{3}: 39 \quad(30 \mathrm{~nm})\right| \mathrm{Alq}_{3} \quad(20 \mathrm{~nm}) \mid \mathrm{Mg}-\mathrm{Ag}$ $(200 \mathrm{~nm})$. The OLED presented maximum brightness of $18,400 \mathrm{~cd} / \mathrm{m}^{2}$ at $13 \mathrm{~V}$ exhibiting a unique constant $\mathrm{CE}$ of $5.2 \mathrm{~cd} / \mathrm{A}$ at a wide current density range of $1-500 \mathrm{~mA} / \mathrm{cm}^{2}$ at different doping concentrations, with relatively narrow emission bands. The bright orange-red emitter 39 did not show any substantial drop in efficiency with increasing dopant concentration and/or current density and can function as a suitable material in passive matrix display which demands high excitation density. The emission wavelength can also be tuned to develop not only different color producing devices, but also whiteemitting OLED (WOLED).

\section{Red emitters with AIE and TADF properties}

Aggregation-induced emission (AIE) can augment solid-phase luminescence intensity by suppressing exciton annihilation and aggregation-induced luminescence quenching. Certain molecules (AIEgens) can aggregate to show significantly enhanced emission in solid state compared to its individual molecular form. Their molecular motions are arrested in the aggregate form due to unique structures and stacking modes. The use of AIEgens can overcome the issues of aggregation-induced quenching, and enable concentration unaffected doping or even non-doped EMLs for OLEDs [127-130]. Generally, the fluorophores can use only $25 \%$ singlet excitons in an OLED. Though small singlet-triplet energy gaps and high photoluminescence QY are essential features for TADF emitters, high-performance red TADF materials are difficult to achieve. This is because the electron and hole should be decoupled on the spatially separated frontier orbitals to achieve the small energy gap, which would possibly reduce the ICT resulting in low QY. The following examples demonstrate the design and synthesis of AIE-TADF NI derivatives as red emitters for OLEDs.

Recently, two red emitters 40 and $\mathbf{4 1}$ have been developed by $\mathrm{Wu}$ et al. with strongly electron-accepting NI component and electron-donating nonpolar groups such as $10-H$-phenothiazine or 9,9dimethyl-9,10-dihydroacridine connected through 2,6-dimethylphenyl as a $\pi$-linker (Fig. 14a) [131]. The molecules with D- $\pi$-A architecture were synthesized 
(a)<smiles>CC(=O)O[C@H](C)c1cc(Br)cc(C)c1N</smiles><smiles>Cc1cc(Br)cc(C)c1N1C(=O)c2cccc3cccc(c23)C1=O</smiles>

$-2.4$

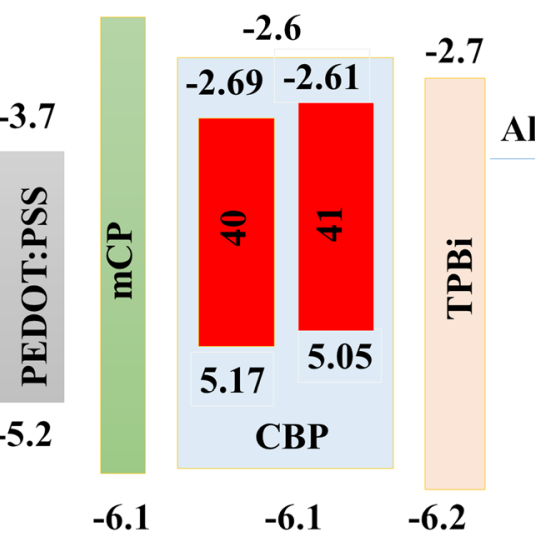

40<smiles>CC1(C)c2ccccc2Nc2ccccc21</smiles><smiles>CC1(C)c2ccccc2Nc2ccccc21</smiles><smiles>Cc1cc(N)cc(C)c1N1C(=O)c2cccc3cccc(c23)C1=O</smiles>

$\mathrm{Pd}(\mathrm{OAc})_{2},(\mathrm{t}-\mathrm{Bu})_{3} \mathrm{PHBF}_{4}$ $\mathrm{K}_{2} \mathrm{CO}_{3}$

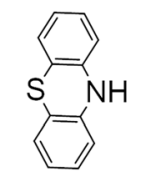<smiles>c1ccc2c(c1)Nc1ccccc1S2</smiles>

41<smiles>Cc1cc(N)cc(C)c1N1C(=O)c2cccc3cccc(c23)C1=O</smiles>

ITO

$-6.1$

$-6.1$

$-6.2$

(b)<smiles>Cc1ccc(N2C(=O)c3cccc4c(N(c5ccc(-c6ccccc6)cc5)c5ccc6c(c5)C(C)(C)c5ccccc5-6)ccc(c34)C2=O)cc1-c1ccccc1</smiles><smiles>C=CC(=C)c1ccc2c3c(cccc13)C(=O)N(c1cc(-c3ccccc3)c(C)c(-c3ccccc3)c1)C2=O</smiles>

Figure 14 Multilayer OLEDs with D- $\pi$-A structures and AIE active TADF [56, 131].

via Buchwald-Hartwig $\mathrm{C}-\mathrm{N}$ coupling utilizing a bromide intermediate and exhibited unique AIE and TADF characteristics. The twisted confirmation due to the $\pi$ - bridge was responsible for restriction in the intermolecular rotation (RIR) leading to AIE property enabling high solid-state red emission, with an internal QY of 55\% and 39\% for $\mathbf{4 0}$ and 41, respectively. Moreover, their twisted structures led to efficient HOMO and LUMO separation and resulted in small energy gaps between lowest singlet (S1) and triplet (T1) excited states. Highly effective RISC process was realized to convert triplet to singlet excitons for robust TADF emission in these molecules. They exhibited good thermal stability for wide range of 
(a)<smiles>[R]c1cc2cc3c([R])cccc3c(=O)oc(=O)c-2c1</smiles>
$\mathrm{R}_{1}=\mathrm{H}, \mathrm{R}_{2}=\mathrm{Br}$ i)

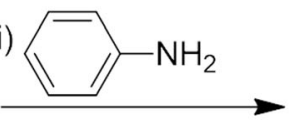

ii)<smiles>CC1(C)c2ccccc2Nc2ccccc21</smiles>

$\mathrm{NaOBu}, \mathrm{TtBuP}$, $\mathrm{Pd}_{2}(\mathrm{dba})_{3}$<smiles>[R2]c1cc2c3c(cccc3c1[R])C(=O)N(c1ccccc1)C2=O</smiles>

$44 a-b$

(b)
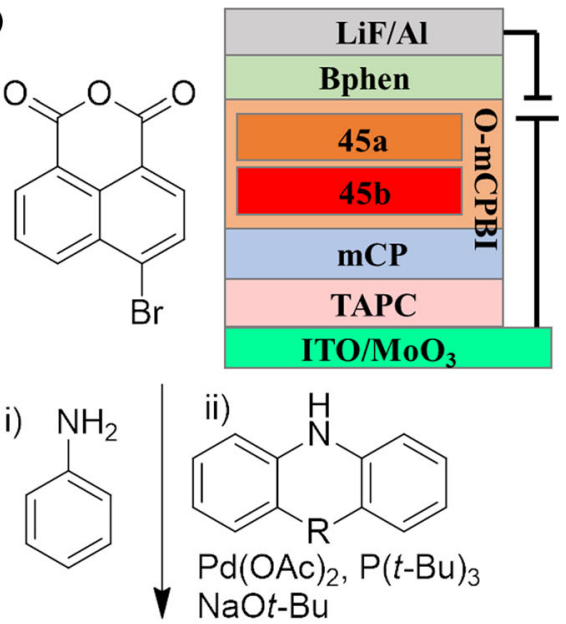

$\checkmark \mathrm{NaOt}-\mathrm{Bu}$

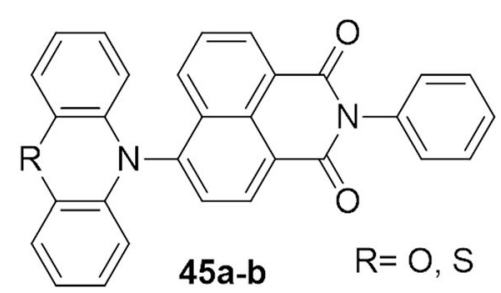

Figure 15 Synthesis and device architecture of TADF red emitters with a strong electron-deficient benzoisoquinoline-1,3-dione [132] and b phenoxazine or phenothiazine donor moieties [133].

temperatures of $\sim 350{ }^{\circ} \mathrm{C}$ with high melting points. Red-emitting device ITO I PEDOT:PSS $(40 \mathrm{~nm}) \mid \mathrm{mCP}$ $(20 \mathrm{~nm})$ |CBP: 40 or $\mathbf{4 1}(15 \mathrm{~nm}, \mathbf{1 2 \%}$ doping) |TPBi $(40 \mathrm{~nm})|\operatorname{LiF}(1 \mathrm{~nm})| \mathrm{Al}(120 \mathrm{~nm})$ was fabricated, and the device with $\mathbf{4 1}$ as red emitter showed better performance with $7.13 \%$ of EQE. 1,3-bis-(N-carbazolyl)benzene (mCP) and TPBi served as HTL and ETL, correspondingly, in the devices.

Chen et al. synthesized two D- $\pi$-A type of molecules 42 and 43 which have arylamine donors and central naphthalamine acceptor core capable of exhibiting AIE-delayed fluorescence (AIE-DF) and TADF properties [56]. The target molecules were obtained by Suzuki coupling, Ullmann reaction or Buchwald-Hartwig reaction between the boric acid, its ester or secondary amine derivatives with the bromide intermediate (Fig. 14b). The incorporation of $N$-([1,1'-biphenyl]-4-yl)-9,9-dimethyl-9H-fluoren-2-amine and 2,6-diphenyl-4-toluene in 42 introduced large steric-hindrance, improved the QY and inhibited $\pi-\pi$ stacking and strong molecular associations in the aggregate form, resulting in AIE, whereas in 43 , the presence of the $\pi$-bridge increased the fluorescence rate constant and QY. Both the molecules were thermally stable up to $440{ }^{\circ} \mathrm{C}$. Non-doped devices with 42 and 43 exhibited lower performance compared to CBP-hosted devices, attributed to the low photoluminescence QY and triplet exciton utilization efficiency. As dilution of emitters in the host matrix is possible in the host-guest system, efficiency of the device can further be enhanced by an efficient Förster energy transfer. Based on this concept, a multilayer OLED was prepared with the structure: ITOIHAT-CN $\quad(15 \mathrm{~nm})$ ITAPC $\quad(40 \mathrm{~nm})$ ITcTa $(5 \mathrm{~nm}) \mid x \quad$ wt $\%-42$ or $\quad 43: \mathrm{CBP} \quad(20 \mathrm{~nm}) \mid \mathrm{TmPyPB}$ $(40 \mathrm{~nm})|\operatorname{LiF}(1 \mathrm{~nm})| \mathrm{Al}(100 \mathrm{~nm})$. Doped OLED with CBP as host and 5 wt \% of $\mathbf{4 2}$ and 43 as dopants could produce a CE of 14.7 and $28.0 \mathrm{~cd} \mathrm{~A}^{-1}$ as well as EQE of 4.81 and $7.59 \%$, correspondingly. 2,3,6,7,10,11Hexacyano-1,4,5,8,9,12-hexaazatriphenylene (HAT$\mathrm{CN}$ ) and $\mathrm{LiF}$ served as hole injection layer (HIL) and EIL, respectively. 1,1-Bis(4-di-p-tolylaminophenyl)cyclohexane (TAPC) and (3,3'-[5'-[3-(3-pyridinyl)phenyl][1,1':3',1' '-terphenyl]-3,3' '-diyl]bispyridine (TmPyPB) were used as the HTL and ETL, respectively. However, peak efficiencies decreased with increase in dopant concentration. A thin TcTa layer was introduced at the EML/HTL interface in order to lessen the hole injection barrier between CBP-hosted EML and TAPC. Sequential charge trapping occurred due to the larger band gap of CBP compared to that of $\mathbf{4 2}$ and $\mathbf{4 3}$ as dopants. Moreover, 
TmPyPB having a low HOMO level was used to prevent hole leakage and permit a better confinement of excitons and charge carriers within the EML. Nondoped EML displayed orange and red emission with maximum EQE of 1.53 and $1.39 \%, \mathrm{CE}$ of 2.44 and $3.71 \mathrm{~cd} \mathrm{~A}^{-1}$ and PE of 1.85 and $2.39 \mathrm{~lm} \mathrm{~W}^{-1}$ for 42 and 43 , respectively. The CIE coordinates of redemitting CBP-free device with derivative 42 was very close to National Television Standards Committee (NTSC) standard red. The doped devices based on $\mathbf{4 2}$ and 43 displayed hypsochromic shift and narrow EL spectra compared to host-free device, with CIE color ranging from orange to red and green to orange, respectively, with increasing dopant concentration.

Two red-emitting donor-acceptor TADF emitters (44a-b) with strong electron-deficient benzoisoquinoline-1,3-dione were prepared by Yun et al. by treating bromo NI compounds with aniline and subsequent reaction with 9,9-dimethyl-9,10- dihydro acridine (Fig. 15a) [132]. Both the molecules exhibited charge transfer property and emitted in red region around 578 and $601 \mathrm{~nm}$. Multilayer devices were prepared by using these emitters as dopants with configuration: ITO | PEDOT:PSS | TAPC I mCP I CBP: TPBi:44a-b (25 nm, 5\% doping) | TSPO1 | TPBi | $\mathrm{LiF} \mid \mathrm{Al}$. EL peak for these devices was around $600 \mathrm{~nm}$ with color coordinates of the $44 \mathrm{a}$ and $44 \mathrm{~b}$ as $(0.56,0.44)$ and $(0.54,0.46)$, respectively. Recently Wang et al. have reported TADF active red emitters (45a-b) by attaching an electron-deficient NI acceptor moiety with a phenoxazine or phenothiazine donor moiety (Fig. 15b) [133]. The two emitters exhibited distinct TADF characteristics with small energy gaps between the lowest singlet and triplet excited states, which originated from the well-separated HOMO and LUMO levels. These emitters are thermally stable up to $310{ }^{\circ} \mathrm{C}$ and exhibited solid-state emission at 588 and $600 \mathrm{~nm}$ for $45 \mathbf{a}-\mathbf{b}$. Multilayer devices were fabricated with the design: ITO $\left|\mathrm{MoO}_{3}\right|$ TAPC I mCP | o-mCPBI: 45a-b (10 wt\%) Bphen I Li$\mathrm{F} \mid \mathrm{Al}$. Both the devices exhibited relatively small efficiency roll-offs. The maximum power efficiency values of 14.8 and $9.8 \mathrm{lmW}^{-1}$ and EQE values reducing to $9.4 \%$ and $6.0 \%$ at a luminance of 1000 $\mathrm{Cdm}^{-2}$ were realized for devices with $45 \mathrm{a}$ and $45 \mathrm{~b}$, respectively.

NI moiety on its own does not display any red emission in the absence of extended conjugation. Hence, incorporation of bulkier aromatic substitutions electron-releasing moieties at the $\mathrm{C} 4$ site of $\mathrm{NI}$ core can not only alter the emissions from blue to red, but also augment the fluorescence QE. Thus, designing molecules with D-linker-A skeleton that combine both TADF and AIE features can greatly improve the efficiency of OLEDs. All the EMLs were doped with CBP and $\mathrm{Alq}_{3}$. Though the development of these types of devices are in progress, an EQE of $13.6 \%$ was achieved till date. Devices with CBP have shown better performance than devices with $\mathrm{Alq}_{3}$. Highest CE was observed in red emitters in comparison with other color emitters of NI.

\section{White emitters}

White organic and white polymeric light-emitting diodes (WOLEDs and WPLEDs) have been lately viewed as one among the emerging technologies [134] because of their impending usage in full-color light-emitting diodes, low-cost backlight for liquidcrystal displays, and several other lighting sources. WOLEDs have garnered special attention due to associated key properties such as energy saving ability, lightweight, flexibility and optimal heat dissipation, thereby replacing the conventional white light sources using large area panels. Typically, in WPLEDSs, white emission is achieved either by using polymer-blended systems comprising of red, green and blue light-emissive polymers, or by doping a small quantity of orange/red-emissive polymer into a blue-emissive polymer. Based on the white light generation, by varying the content of orange/redemitting NI conjugated to blue-emitting polymers and the substantial alterations in the current-voltage responses of the devices centered on these materials, few white-emitting polymers incorporating NI unit were studied as illustrated below.

$\mathrm{Tu}$ et al. developed a white light-emitting polymer 46 by incorporating $0.05-8 \mathrm{~mol} \%$ of orange-emitting NI chromophore into a blue light-emitting polyfluorene system using Yamamoto polycondensation reaction with catalytic amount of $\mathrm{Ni}(0)$ (Fig. 16a) [134]. The NI quantity in the polymer was responsible for the tuned emission. A WPLED with device structure ITO|PEDOT $\quad(40 \mathrm{~nm})|46 \quad(80 \mathrm{~nm})| \mathrm{Ca}$ $(10 \mathrm{~nm}) \mid \mathrm{Al}(100 \mathrm{~nm})$ presented $\mathrm{CE}$ and $\mathrm{PE}$ of $5.3 \mathrm{~cd} /$ $\mathrm{A}$ and $2.8 \mathrm{Lm} / \mathrm{W}$ at $6 \mathrm{~V}$, respectively, with $\mathrm{CIE}$ coordinates at $(0.25,0.35)$ and maximum brightness of $11,100 \mathrm{~cd} / \mathrm{m}^{2}$. The polymer-blended device presented a very stable white light emission in terms of both color and efficiency at different brightness and 
Figure 16 White-emitting NI blended polymers and their device architectures based on combination emission strategy $[134,135]$. (a)

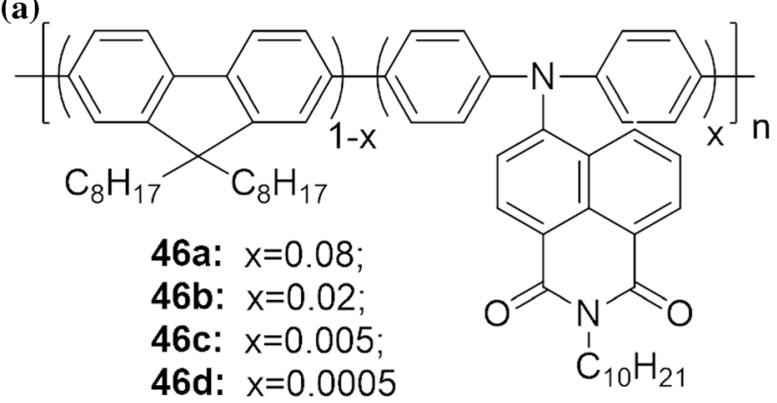

46a-d

(b)

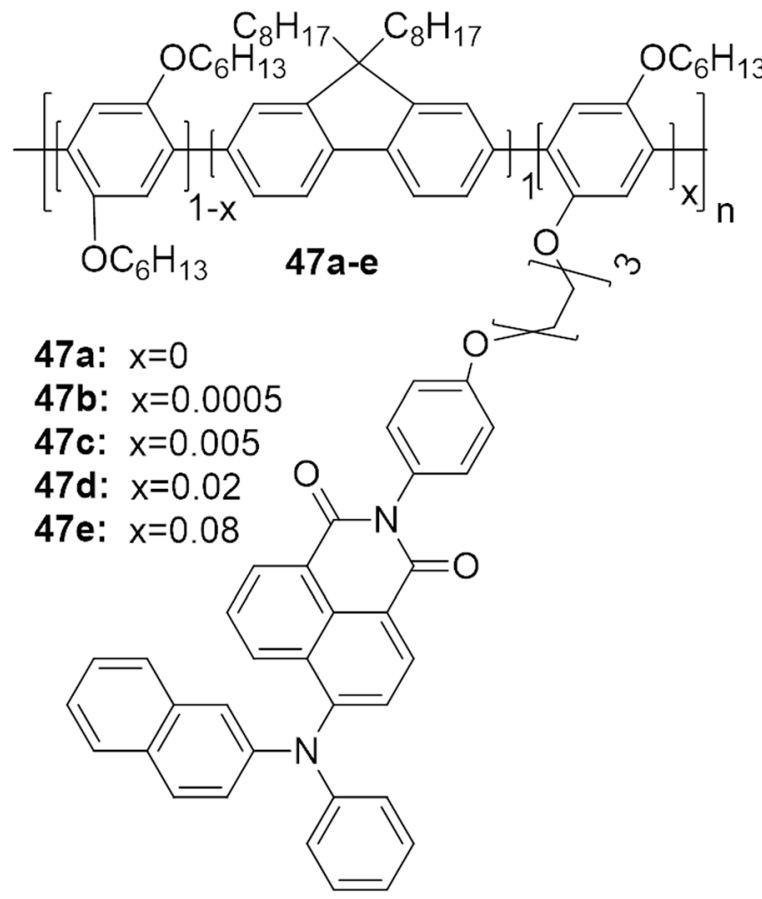

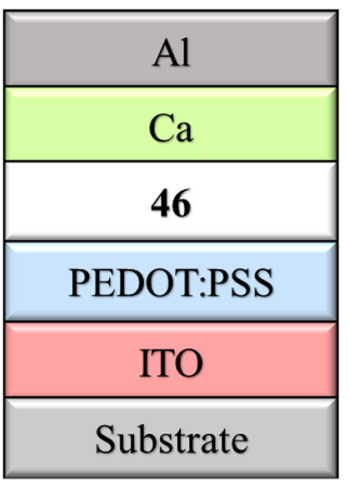

\begin{tabular}{|c|}
\hline $\mathrm{Al}$ \\
\hline $\mathrm{Ba}$ \\
\hline $\mathbf{4 7}$ \\
\hline PEDOT:PSS \\
\hline ITO \\
\hline Substrate \\
\hline
\end{tabular} driving voltage. The chemical doping was advantageous over physical doping because the blended systems displayed lesser CE. The emission from dopant molecules increased with rising driving voltage, which indicated the dependency of the CIE coordinates on the driving voltage.

Later, polymers 47a-e with blue-emisssive poly(fluorine-alt-phenylene) that contained comonomers carrying red-emissive NI pendant units with varying concentration $(0,0.0005,0.005,0.02$ and $0.08 \mathrm{wt} \%$ ) were developed by Coya et al. as luminescent materials for WOLEDs (Fig. 16b) [135]. Devices configured as ITO।PEDOT:PSS | 47ae $|\mathrm{Ba}| \mathrm{Al}$ were emissive at low driving current range of $47-73 \mu \mathrm{A}$. EL emission was dominated by the NI contribution, which exhibited a redshift with increased concentration of the chromophore. Pure white light emission was observed from the copolymer bearing $0.0005 \%$ chromophoric NI groups of $47 \mathrm{~b}$ with luminous efficiency of $9.42 \mathrm{Cd} / \mathrm{A}$ at $50 \mu \mathrm{As}$ from almost pure white color with CIE coordinates (0.26, $0.30)$ for low currents to stable cool white $(0.21,0.23)$ for different polymers. Increase in NI content (47d-e) resulted in stable green to orange fluorescence with efficiency of $6.7 \mathrm{Cd} / \mathrm{A}$.

The emission color was dependent on the concentration of NI in the copolymer. Higher concentration of these derivatives showed green to orange emission with decreased CE. Small molecules used in WOLED with triplet excitons in the radiative recombination process perform better as they involve spin-orbital coupling allowing radiative decay and are also lowcost material [136]. Using a single and multilayer TADF emissive layer, very low turn-on voltages (V), 


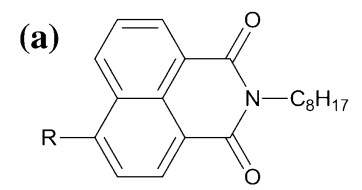

48a-f
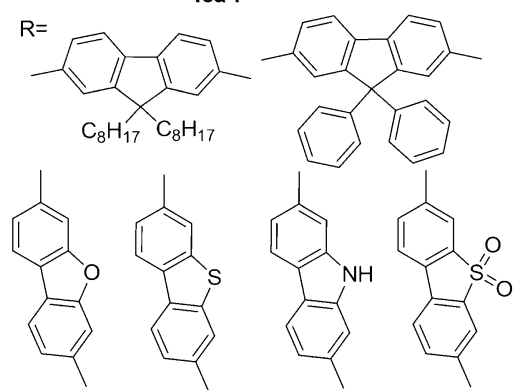

(b) $\mathrm{H}_{3} \mathrm{CO}$

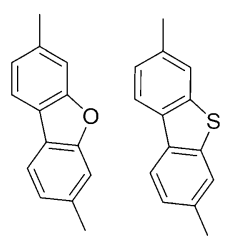

(c) $\mathrm{O} \quad \mathrm{R}=-\mathrm{OCH}_{2} \mathrm{CH}_{2} \mathrm{OCH}_{3}$

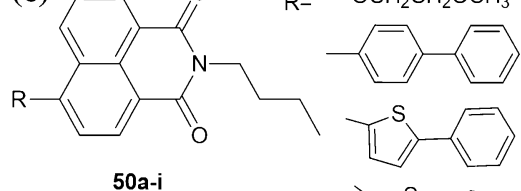

(d)

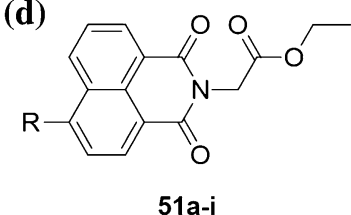

$\mathrm{R}=-\mathrm{COCH}_{3}$

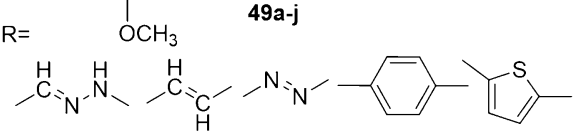

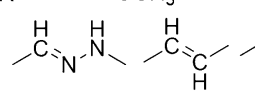

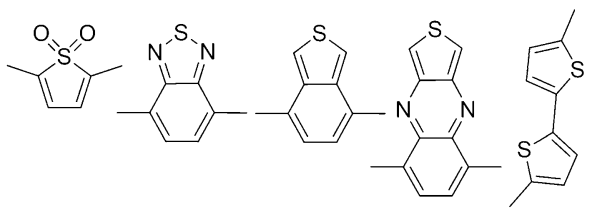

(e)
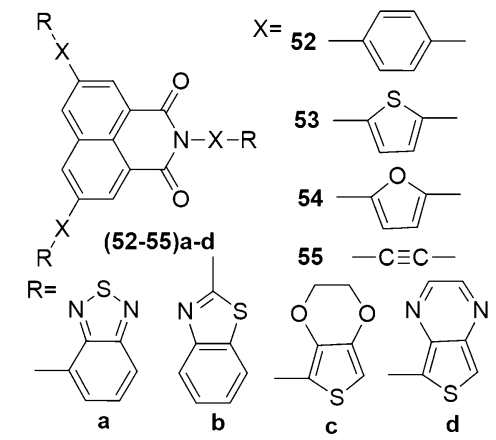

Figure 17 Molecular structures of NI derivatives identified as $\mathbf{a}, \mathbf{b}, \mathbf{c}$ potential light-emitting materials [139-141] $\mathbf{d}, \mathbf{e}$ as hole or electron transport materials $[142,143]$ through theoretical investigations.

high PE $(\mathrm{lm} / \mathrm{W}), \mathrm{CE}(\mathrm{cd} / \mathrm{A})$, and even a maximum of 28\% EQE with a CIE coordinate close to standard $(0.33,0.33)$ can be achieved [93].

\section{Theoretical studies}

Theoretical studies play a significant role in developing materials with desired features for preferred applications. Several investigations have established the relationship between theory and experiment that can provide useful insights into the behavioral aspects of molecules designed for distinctive applications [137, 138]. Theoretical probing bestows exhaustive understanding of the optical, electronic, and charge-transporting characteristics of a designed molecule, and wisely tune the substituents attached to achieve a final OLED material with the most desired properties.

D-A molecular arrangement of NI derivatives 48af with fluorene substituents was investigated by Chai et al. to understand their optical, electronic and charge transfer features for OLED application (Fig. 17a) [139]. The electronic and optical characteristics were influenced by the substituent units in fluorene skeleton. All molecules demonstrated potential electron and hole transport properties, while derivatives incorporating dibenzothiophene fragment could function only as a hole transport material. D- $\pi$-A bipolar molecules 49aj with triphenylamine components as blue lightemitting donors, NI unit as acceptors, and diverse $\pi$ conjugated spacers with vertical absorption and emission transitions were designed by Jin et al. as presented in Fig. 17b [140]. Varying the electron-donating $\pi$-conjugated spacers of $\mathbf{4 9} \mathbf{a}-\mathbf{j}$ is an extremely favorable approach to develop hole transport luminescent materials for OLED. Sun et al. designed a series of N-butyl-1,8-naphthalimide derivatives 50a-i as luminophores for OLEDs (Fig. 17c) [141]. Among these molecules, $\mathbf{5 0} \mathbf{g}$ and $\mathbf{5 0 i}$ with benzo[c]thiophene and benzo[ $[d]$ thieno[3,2- $b]$ thiophene units exhibited hole-transporting features. The FMOs analysis of all these molecules 48-50 revealed that the absorption and emission process were ICT-characterized. The calculations suggested that the substituent groups in the molecular structure affect the optical and 
Table 1 Performance of NI derivatives-based OLEDs that emit R/G/B and white colors

\begin{tabular}{|c|c|c|c|c|c|c|c|}
\hline Molecule number & $\begin{array}{l}\lambda_{\text {emission }} \\
(\mathrm{nm})\end{array}$ & $\operatorname{CIE}(x, y)$ & $\begin{array}{l}\text { Lum. }(\mathrm{cd} / \\
\left.\mathrm{m}^{2}\right)\end{array}$ & $\begin{array}{l}\text { Turn-on volt. } \\
\text { (V) }\end{array}$ & $\begin{array}{l}\mathrm{PE}(\mathrm{lm} / \mathrm{W}) \\
\eta_{p}\end{array}$ & $\begin{array}{l}\mathrm{CE}(\mathrm{cd} / \mathrm{A}) \\
\eta_{c}\end{array}$ & $\begin{array}{l}\eta_{\mathrm{EQE}} \\
(\%)\end{array}$ \\
\hline \multicolumn{8}{|l|}{ Blue emitters } \\
\hline 1:4 (Type 1) & - & - & 3600 & 3 & 1.3 & - & 1.7 \\
\hline 1:4 (Type 2) & - & - & 3400 & 3 & 2.3 & - & 3.2 \\
\hline 5a (EML) (I) trilayer device & 487 & $\begin{array}{c}(0.18, \\
0.33)\end{array}$ & 826 & 7.7 & 0.19 & 0.79 & 0.42 \\
\hline 5a (EML) (II) bilayer device & 485 & $\begin{array}{r}(0.18 \\
0.34)\end{array}$ & 334 & 8.25 & 0.14 & 0.54 & 0.28 \\
\hline 5a (ETL) (III) & 516 & - & 5078 & 9.4 & 1.78 & 8.8 & 1.40 \\
\hline $5 \mathrm{~g}$ (EML) (IV) & - & $\begin{array}{c}(0.19 \\
0.28)\end{array}$ & 889 & 7.03 & 0.21 & 0.89 & 0.41 \\
\hline $6 \mathrm{~g}(\mathrm{EML})(\mathrm{IV})$ & - & $\begin{array}{r}(0.18 \\
0.28)\end{array}$ & 1072 & 6.92 & 0.23 & 0.96 & 0.47 \\
\hline 5 g (EL \& ETL) (V) & - & - & 1580 & 6.35 & 0.86 & 1.87 & 0.69 \\
\hline $6 \mathrm{~g}(\mathrm{EL} \& \mathrm{ETL})(\mathrm{V})$ & - & - & 1681 & 6.18 & 0.98 & 1.89 & 0.71 \\
\hline $5 \mathrm{~g}(\mathrm{VI})$ & - & - & 5341 & 9.23 & 1.82 & 8.90 & 1.39 \\
\hline $6 \mathrm{~g}(\mathrm{VI})$ & - & - & 5962 & 9.14 & 1.98 & 9.04 & 1.46 \\
\hline 11 & 494 & $\begin{array}{c}(0.23 \\
0.44)\end{array}$ & 3389 & 3.2 & - & - & 3.98 \\
\hline \multicolumn{8}{|l|}{ Green emitters } \\
\hline CBP:12a (EML) + BCP & 530 & $\begin{array}{c}(0.29 \\
0.60)\end{array}$ & 10,404 & 5.8 & 0.96 & 3.77 & 1.11 \\
\hline CBP:12b (EML) + BCP & 531 & $\begin{array}{c}(0.31 \\
0.60)\end{array}$ & 5898 & 6.2 & 0.68 & 2.49 & 0.73 \\
\hline CBP:12b (EML) + BCP & 533 & $\begin{array}{c}(0.25 \\
0.57)\end{array}$ & 877 & 5.5 & 0.32 & 0.93 & 0.27 \\
\hline CBP:12c & 586 & $\begin{array}{r}(0.48 \\
0.48)\end{array}$ & 323 & 3.8 & 0.02 & 0.04 & 0.01 \\
\hline $12 \mathrm{c}$ & 586 & $\begin{array}{c}(0.48, \\
0.47)\end{array}$ & 133 & 4.0 & 0.009 & 0.02 & 0.006 \\
\hline $13 \mathrm{a}$ & 556 & $\begin{array}{r}(0.43, \\
0.53)\end{array}$ & 4500 & 10 & 0.12 & 0.65 & - \\
\hline $14 \mathrm{~b}$ & 544 & $\begin{array}{r}(0.37 \\
0.57)\end{array}$ & 2119 & 7 & 0.26 & 0.94 & - \\
\hline $15 \mathrm{a}$ & 532 & $\begin{array}{r}(0.38 \\
0.57)\end{array}$ & 1100 & 6 & 0.12 & 0.56 & - \\
\hline 16 & 530 & $\begin{array}{c}(0.42 \\
0.54)\end{array}$ & 3563 & - & 0.55 & - & 0.2 \\
\hline $17 \mathrm{a}$ & 539 & - & 87 & 12 & - & - & - \\
\hline $17 \mathrm{~b}$ & 539 & - & 90 & 11 & - & - & - \\
\hline $17 \mathrm{c}$ & 540 & - & 120 & 11 & - & - & - \\
\hline $17 d$ & 535 & - & 110 & 11 & - & - & - \\
\hline $17 \mathrm{f}$ & 532 & - & 98 & 10 & - & - & - \\
\hline $18 \mathrm{a}$ & 539 & - & 238 & 7 & - & - & - \\
\hline $18 \mathrm{~b}$ & 538 & - & 260 & 8 & - & - & - \\
\hline $18 \mathrm{c}$ & 534 & - & 224 & 8 & - & - & - \\
\hline
\end{tabular}


Table 1 continued

\begin{tabular}{|c|c|c|c|c|c|c|c|}
\hline Molecule number & $\begin{array}{l}\lambda_{\text {emission }} \\
(\mathrm{nm})\end{array}$ & $\operatorname{CIE}(x, y)$ & $\begin{array}{l}\text { Lum. }(\mathrm{cd} / \\
\left.\mathrm{m}^{2}\right)\end{array}$ & $\begin{array}{l}\text { Turn-on volt. } \\
\text { (V) }\end{array}$ & $\begin{array}{l}\mathrm{PE}(\operatorname{lm} / \mathrm{W}) \\
\eta_{p}\end{array}$ & $\begin{array}{l}\mathrm{CE}(\mathrm{cd} / \mathrm{A}) \\
\eta_{c}\end{array}$ & $\begin{array}{l}\eta_{\mathrm{EQE}} \\
(\%)\end{array}$ \\
\hline 21 & 538 & $\begin{array}{r}(0.38 \\
0.55)\end{array}$ & 3031 & 8 & - & 6.9 & - \\
\hline 23 & 535 & $\begin{array}{r}(0.39 \\
0.55)\end{array}$ & 643 & 15 & - & - & - \\
\hline \multicolumn{8}{|l|}{ Orange emitters } \\
\hline 24 & 540 & $\begin{array}{r}(0.37 \\
0.54)\end{array}$ & 143 & 13.7 & - & - & 0.85 \\
\hline 25 & 562 & $\begin{array}{r}(0.43 \\
0.51)\end{array}$ & 124 & 12.5 & - & - & 0.91 \\
\hline $26 \mathrm{a}$ & - & $\begin{array}{r}(0.46 \\
0.52)\end{array}$ & - & - & - & - & - \\
\hline $26 b$ & - & $\begin{array}{r}(0.48 \\
0.52)\end{array}$ & - & - & - & - & - \\
\hline 27 & 597 & - & - & 3 & 3.90 & 9.93 & 4.59 \\
\hline 28 & 584 & - & - & 3 & 1.77 & 5.74 & 2.20 \\
\hline 29 & 641 & $\begin{array}{r}(0.62 \\
0.38)\end{array}$ & 773 & 4 & 7.3 & 9.6 & 9.2 \\
\hline 30 & 590 & $\begin{array}{r}(0.54 \\
0.45)\end{array}$ & 2350 & 3 & 51.4 & 49.2 & 20.3 \\
\hline $31 \mathrm{a}$ & 592 & - & - & 3.4 & 26.6 & 28.8 & 12.3 \\
\hline $31 b$ & 592 & - & - & 3.4 & 28 & 2.8 .5 & 12.4 \\
\hline \multicolumn{8}{|l|}{ Red emitters } \\
\hline $32 d$ & 620 & - & 15.5 & 14 & - & - & - \\
\hline $\begin{array}{l}34 \text { (TFDF):35 (emitting } \\
\text { dopant) }\end{array}$ & - & - & 16,840 & - & - & 7.2 & 3.59 \\
\hline 36: $\operatorname{Ir}(\mathrm{piq})_{2}(\mathrm{acac})(10 \%)$ & - & - & 15,300 & 3.5 & 7.1 & 10.8 & 13.6 \\
\hline 36: $\operatorname{Ir}(\mathrm{piq})_{2}(\mathrm{acac})(15 \%)$ & - & - & 14,900 & 3.5 & 6.6 & 9.7 & 12.6 \\
\hline 36: $\operatorname{Ir}(\mathrm{piq})_{2}(\mathrm{acac})(25 \%)$ & - & - & 12,000 & 3.7 & 2.7 & 5.2 & 7.0 \\
\hline $34: 37(14 \%)$ & 657 & $(0.67,0.32)$ & 2660 & 3.1 & - & 0.7 & 1.8 \\
\hline $34: 38(2 \%)$ as EML & 636 & $(0.62,0.37)$ & 10,900 & 3.1 & - & 1.9 & 2.1 \\
\hline $34: 38(4 \%)$ & 644 & $(0.65,0.34)$ & 6600 & 3.1 & - & 1.1 & 1.8 \\
\hline $\mathrm{Alq}_{3}: 39(1 \%)$ & 576 & - & 18,400 & 3.5 & - & 5.2 & - \\
\hline CBP:40 (12\%) & 635 & $\begin{array}{r}(0.59 \\
0.40)\end{array}$ & 4634 & 6.0 & 9.3 & 16.8 & 7.13 \\
\hline CBP:41 (12\%) & 570 & $\begin{array}{r}(0.37 \\
0.42)\end{array}$ & 2312 & 5.0 & 5.2 & 12.4 & 5.38 \\
\hline 42 & 628 & $\begin{array}{r}(0.65 \\
0.34)\end{array}$ & 10,200 & 2.9 & 1.85 & 2.44 & 1.53 \\
\hline CBP:42 (5\%) & 575 & $\begin{array}{r}(0.49 \\
0.49)\end{array}$ & 59,490 & 3.3 & 10.98 & 14.69 & 4.80 \\
\hline 43 & 583 & $\begin{array}{r}(0.53 \\
0.46)\end{array}$ & 14,310 & 2.9 & 2.39 & 3.71 & 1.39 \\
\hline CBP:43 & 538 & $\begin{array}{r}(0.34 \\
0.59)\end{array}$ & 51,220 & 3.4 & 20.97 & 27.95 & 7.59 \\
\hline $44 a$ & - & $\begin{array}{r}(0.54 \\
0.46)\end{array}$ & - & - & 9.9 & - & 4.6 \\
\hline
\end{tabular}


Table 1 continued

\begin{tabular}{|c|c|c|c|c|c|c|c|}
\hline Molecule number & $\begin{array}{l}\lambda_{\text {emission }} \\
(\mathrm{nm})\end{array}$ & $\operatorname{CIE}(x, y)$ & $\begin{array}{l}\text { Lum. (cd/ } \\
\left.\mathrm{m}^{2}\right)\end{array}$ & $\begin{array}{l}\text { Turn-on volt. } \\
\text { (V) }\end{array}$ & $\begin{array}{l}\mathrm{PE}(\operatorname{lm} / \mathrm{W}) \\
\eta_{p}\end{array}$ & $\begin{array}{l}\mathrm{CE}(\mathrm{cd} / \mathrm{A}) \\
\eta_{c}\end{array}$ & $\begin{array}{l}\eta_{\mathrm{EQE}} \\
(\%)\end{array}$ \\
\hline $44 b$ & - & $\begin{array}{r}(0.56 \\
0.44)\end{array}$ & - & - & 18.7 & - & 9.5 \\
\hline $45 \mathrm{a}$ & 624 & $\begin{array}{r}(0.61 \\
0.38)\end{array}$ & 3197 & 3.2 & 14.8 & 15.2 & 13.0 \\
\hline $45 b$ & 632 & $\begin{array}{c}(0.63 \\
0.36)\end{array}$ & 2325 & 3.4 & 9.8 & 10.8 & 11.4 \\
\hline \multicolumn{8}{|l|}{ White emitters } \\
\hline Polymer with $0.05 \% 46$ & - & $(0.25,0.35)$ & 11,100 & - & 2.8 & 5.3 & - \\
\hline Copolymer with $0.0005 \% 47$ & - & $\begin{array}{c}(0.26 \\
0.30)\end{array}$ & - & - & - & 9.42 & - \\
\hline
\end{tabular}

electronic properties and these molecules are promising candidates for OLED application.

Optoelectronic properties like charge transfer and luminescence of a series of NI materials that carry electron-donating and aromatic groups 51a-i were investigated by Jin et al.(Fig. 17d) [142]. The optical and electronic properties varied with substitution at 4th position of NI derivatives. However, ICT property of substituents was not significant and stability of the molecules did not change with the substitution. Later in 2015 same research group studied starshaped D- $\pi$-A small molecules (52-55)a-d with NI structures for OLED application (Fig. 17e) [143], and using the FMO and local density of states analysis, the vertical electronic transitions of absorption and emission were characterized as ICT. The end groups and spacers affected the optical properties. These star-shaped compounds had lower band gap, hence extended the absorption spectra to longer wavelengths and especially 54a could be used as hole or electron transport material.

\section{Summary}

Highly intense luminescence and excellent carrier mobility that arises from planar molecular geometry and extended $\pi$-conjugated systems are the most desired features of OLED materials. In this context, the possibility of grafting a large variety of auxochromic groups into the NI skeleton, and properties of the surrounding medium that can enable finetuning of the emission colors for OLEDs are illustrated in this review. The device performances with NIs having various structural frameworks that emit $\mathrm{R} / \mathrm{G} / \mathrm{B}$ and white colors, respectively, are summarized in the Table 1. The luminescence intensity is related to the extent of conjugation allowed within the molecule, which escalates based on the interactions between the donor and acceptor elements of the molecule. Hence by exploiting the scope of introduction of different substituents, a range of NI derivatives have been prepared and utilized in both small molecule blue, red, orange, green-emitting OLEDs and polymer-based WOLEDs. Typically, proper selection of donor as well as acceptor moieties enable to achieve suitable separation of the HOMO and LUMO energy levels in the D-A-type molecular structure for OLED fabrication. Moreover, emission from ICT states contribute immensely to EL of these devices. Search for newer and efficient charge-transporting functional materials for OLED applications holds great importance.

\section{Future prospects}

Organic solid-state lighting is now progressing toward technical lighting and general illumination from decorative applications. This evolving transition demands device architectures with higher efficiency, better color purity, increased lifetime, and reduced production costs. Few important aspects that need technical advancements are highlighted below.

Development of blue emitters is one of the challenging research areas for material chemists as generally they have lesser thermal stability, luminescent efficiency and lifetime, as well as narrow emission wavelength for color purity compared to green and red emitters [144, 145]. Besides, low electron affinities and wide energy band gap contribute to higher barrier for electron injection, resulting in poorer device 
performance. Though efficient blue-emitting $p$-type materials have been constructed and this review portrays investigations on $n$-type NI derivatives as blue OLED materials, more studies on stable and efficient $n$-type blue materials are essential for commercialization of blue OLEDs.

While being used as red dopants in commercial applications, high-performance $n$-type red emitters are much sought after due to compromised color purity, chemical stability and device efficiency. NI derivatives with higher fluorescence $\mathrm{QE}$, narrower FWHM (full width at half maximum) and far-infrared emission are extremely required. Though design of triplet red emitters with extended lifetime have been achieved, their efficiency decreases with increase in brightness [146], which challenges their use in passive dot-matrix displays. Red-emitting compounds possess low energy gap between HOMO and LUMO levels which leads to high non-radiative transition rate of exciton in some cases and finally results in the quenching of emission. TADF materials can solve this problem to some extent, and though some of red TADF materials are reported, further investigation can be oriented in this direction. In addition, except few reports with devices of around $20 \%$ EQE, most red TADF materials featured only 5-15\% EQE range and lag behind in displaying high performance in OLED applications [121]. Besides, design of highly efficient TADF-AIEgens which can facilitate high concentration doping combined with red emission beyond $600 \mathrm{~nm}$ are of high demand as they offer efficient and enhanced solid-state luminescence. The molecular design of red-emitting TADF featured AIEgens with both strong ICT state and twisted molecular conformation are also of extreme emphasis.

Even though it gives the impression that the triplet energy level of NI with maximum phosphorescence near $540 \mathrm{~nm}$ [147] may hinder their possible use only as a host to red and orange dopants, the prospects of exploiting these molecules for efficient electro-phosphorescence from blue or green devices can be further investigated. Moreover, an important factor for degradation of OLED is its operational current.
Reducing the operational current and retaining luminescence is a task which also demand further attention [148-150]. Innovations in WOLED architectures that can allow color tuning from cool to warm white or even full-color tunability are highly desired. Host materials for green technology devices with adjustable brightness levels that become even more efficient when dimmed are also looked for. Though the main focus in current WPLED technology is to reduce manufacturing costs and to improve mass-production processes, WPLED efficiency with very low $\mathrm{Cd} / \mathrm{A}$ values is still a major concern [151, 152]. Accordingly, there exists a substantial necessity for novel organic semiconductors that uniquely combine enhanced processability, stability and performance with efficient charge transport properties and light emission. Thin, flexible and transparent devices of almost any shape, which can emit from both sides, can enable a completely new experience that is both attractive and highly efficient.

Thus, in spite of extensive research that have been conducted toward refining the stability, color tunability and efficiency of OLEDs either through molecular engineering or modifying device configuration [134, 136], design and synthesis of new materials for desired colors, maximization of the EQE, and modes of addressing fabrication of full-color display devices with optimized resolution continue to remain a challenge. We anticipate that this comprehensive report would benefit the researchers who are actively engaged or planning to enter the arena on OLED materials search and could kindle further research in this area.

\section{Funding}

Open access funding provided by Manipal Academy of Higher Education, Manipal.

\section{Declarations}

Conflict of interest The authors declare that they have no conflict of interest. 
Open Access This article is licensed under a Creative Commons Attribution 4.0 International License, which permits use, sharing, adaptation, distribution and reproduction in any medium or format, as long as you give appropriate credit to the original author(s) and the source, provide a link to the Creative Commons licence, and indicate if changes were made. The images or other third party material in this article are included in the article's Creative Commons licence, unless indicated otherwise in a credit line to the material. If material is not included in the article's Creative Commons licence and your intended use is not permitted by statutory regulation or exceeds the permitted use, you will need to obtain permission directly from the copyright holder. To view a copy of this licence, visit http://creativecommons.org/licen ses/by $/ 4.0 /$.

\section{References}

[1] Xiao L, Chen Z, Qu B, Luo J, Kong S, Gong Q, Kido J (2011) Recent progresses on materials for electrophosphorescent organic light-emitting devices. Adv Mater 23:926-952. https://doi.org/10.1002/adma.201003128

[2] Fan C, Yang C (2014) Yellow/orange emissive heavy-metal complexes as phosphors in monochromatic and white organic light-emitting devices. Chem Soc Rev 43:6439-6469. https://doi.org/10.1039/c4cs00110a

[3] Zhu M, Yang C (2013) Blue fluorescent emitters: design tactics and applications in organic light-emitting diodes. Chem Soc Rev 42:4963-4976. https://doi.org/10.1039/c3c s35440g

[4] Murawski C, Leo K, Gather MC (2013) Efficiency roll-off in organic light-emitting diodes. Adv Mater 25:6801-6827. https://doi.org/10.1002/adma.201301603

[5] Schmidbauer S, Hohenleutner A, König B (2013) Chemical degradation in organic light-emitting devices: mechanisms and implications for the design of new materials. Adv Mater 25:2114-2129. https://doi.org/10.1002/adma. 201205022

[6] Sasabe H, Kido J (2013) Development of high performance OLEDs for general lighting. J Mater Chem C 1:1699-1707. https://doi.org/10.1039/c2tc00584k

[7] Chen Y, Ma D (2012) Organic semiconductor heterojunctions as charge generation layers and their application in tandem organic light-emitting diodes for high power efficiency. J Mater Chem 22:18718-18734. https://doi.org/10. 1039/c2jm32246c
[8] D'Andrade BW, Forrest SR (2004) White organic lightemitting devices for solid-state lighting. Adv Mater 16:1585-1595. https://doi.org/10.1002/adma.200400684

[9] Raj A, Gupta M, Suman D (2019) Simulation of multilayer energy efficient OLEDs for flexible electronics applications. Procedia Comput Sci 152:301-308. https://doi.org/ 10.1016/j.procs.2019.05.013

[10] Jang J (2006) Displays develop a new flexibility. Mater Today 9:46-52. https://doi.org/10.1016/S1369-7021(06)71 447-X

[11] Yang Z, Song J, Zeng H, Wang M (2019) Organic composition tailored perovskite solar cells and light-emitting diodes: perspectives and advances. Mater Today Energy 14:100338. https://doi.org/10.1016/j.mtener.2019.06.013

[12] Zou SJ, Shen Y, Xie FM, Chen JD, Li YQ, Tang JX (2020) Recent advances in organic light-emitting diodes: toward smart lighting and displays. Mater Chem Front 4:788-820. https://doi.org/10.1039/c9qm00716d

[13] Wang J, Zhang F, Zhang J et al (2013) Key issues and recent progress of high efficient organic light-emitting diodes. J Photochem Photobiol C Photochem Rev 17:69-104. https://doi.org/10.1016/j.jphotochemrev.2013.0 8.001

[14] Duan L, Qiao J, Sun Y, Qiu Y (2011) Strategies to design bipolar small molecules for OLEDs: donor-acceptor structure and non-donor-acceptor structure. Adv Mater 23:1137-1144. https://doi.org/10.1002/adma.201003816

[15] Zou Y, Zou J, Ye T, Li H, Yang C, Wu H, Ma D, Qin J, Cao Y (2013) Unexpected propeller-like hexakis(fluoren-2yl)benzene cores for six-arm star-shaped oligofluorenes: highly efficient deep-blue fluorescent emitters and good hole-transporting materials. Adv Funct Mater 23:1781-1788. https://doi.org/10.1002/adfm.201202286

[16] Burroughes JH, Bradley DDC, Brown AR, Marks RN, Mackey K, Friend RH, Burns PL, Holmes AB (1990) Light-emitting diodes based on conjugated polymers. Nature 347:539-541. https://doi.org/10.1038/347539a0

[17] Chen HW, Lee JH, Lin BY, Chen S, Wu ST (2018) Liquid crystal display and organic light-emitting diode display: present status and future perspectives. Light Sci Appl 7:17168. https://doi.org/10.1038/1sa.2017.168

[18] Guo J, Zhao Z, Tang BZ (2018) Purely organic materials with aggregation-induced delayed fluorescence for efficient nondoped OLEDs. Adv Opt Mater 6:1-11. https://doi.org/ 10.1002/adom.201800264

[19] Xu T, Zhang YX, Wang B, Huang CC, Murtaza I, Meng H (2017) Highly simplified reddish orange phosphorescent organic light-emitting diodes incorporating a novel carrierand exciton-confining spiro-exciplex-forming host for 
reduced efficiency roll-off. ACS Appl Mater Interfaces 9:2701-2710. https://doi.org/10.1021/acsami.6b13077

[20] Li Y, Liu JY, Di ZY, Cao YC (2017) Recent advancements of high efficient donor-acceptor type blue small molecule applied for OLEDs. Mater Today 20:258-266. https://doi. org/10.1016/j.mattod.2016.12.003

[21] Eritt M, May C, Leo K, Toerker M, Radehaus C (2010) OLED manufacturing for large area lighting applications. Thin Solid Films 518:3042-3045. https://doi.org/10.1016/j. tsf.2009.09.188

[22] Li G, Yu X, Liu D, Liu X, Li F, Cui H (2015) Label-free electrochemiluminescence aptasensor for 2,4,6-trinitrotoluene based on bilayer structure of luminescence functionalized graphene hybrids. Anal Chem 87:10976-10981. https://doi.org/10.1021/acs.analchem.5b02913

[23] Hofle S, Schienle A, Bernhard C, Bruns M, Lemmer U, Colsmann A (2014) Solution processed, white emitting tandem organic light-emitting diodes with inverted device architecture. Adv Mater 26:5155-5159. https://doi.org/10. 1002/adma.201400332

[24] Jou JH, Wang CJ, Lin YP et al (2008) Color-stable, efficient fluorescent pure-white organic light-emitting diodes with device architecture preventing excessive exciton formation on guest. Appl Phys Lett 92:223504. https://doi.org/ 10.1063/1.2926423

[25] Hofle S, Bernhard C, Bruns M, Kubel C, Scherer T, Lemmer U, Colsmann A (2015) Charge generation layers for solution processed tandem organic light emitting diodes with regular device architecture. ACS Appl Mater Interfaces 7:8132-8137. https://doi.org/10.1021/acsami.5b 00883

[26] Kawata T, Seo S, Shitagaki S et al (2013) Highly efficient OLED devices with device architecture for reducing drive voltage. Dig Tech Pap - SID Int Symp 44:685-688. http s://doi.org/10.1002/j.2168-0159.2013.tb06305.x

[27] Erickson NC, Holmes RJ (2013) Investigating the role of emissive layer architecture on the exciton recombination zone in organic light-emitting devices. Adv Funct Mater 23:5190-5198. https://doi.org/10.1002/adfm.201300101

[28] Kukhta A, Kolesnik E, Grabchev I, Sali S (2006) Spectral and luminescent properties and electroluminescence of polyvinylcarbazole with 1,8-naphthalimide in the side chain. J Fluoresc 16:375-378. https://doi.org/10.1007/s10 895-005-0064-6

[29] Ding G, Xu Z, Zhong G, Jing S, Li F, Zhu W (2008) Synthesis, photophysical and electroluminescent properties of novel naphthalimide derivatives containing an electrontransporting unit. Res Chem Intermed 34:299-308. https://d oi.org/10.1163/156856708783623401
[30] Liu J, Cao J, Shao S, Xie Z, Cheng Y, Geng Y, Wang Y, Jing X, Wang F (2008) Blue electroluminescent polymers with dopant-host systems and molecular dispersion features: Polyfluorene as the deep blue host and 1,8-naphthalimide derivative units as the light blue dopants. J Mater Chem 18:1659-1666. https://doi.org/10.1039/b716234k

[31] Tonzola CJ, Kulkarni AP, Gifford AP, Kaminsky W, Jenekhe SA (2007) Blue-light-emitting oligoquinolines: SYNTHESIS, properties, and high-efficiency blue-lightemitting diodes. Adv Funct Mater 17:863-874. https://doi. org/10.1002/adfm.200600542

[32] Earmme T, Ahmed E, Jenekhe SA (2009) Highly efficient phosphorescent light-emitting diodes by using an electrontransport material with high electron affinity. J Phys Chem C 113:18448-18450. https://doi.org/10.1021/jp907913d

[33] Wu MF, Yeh SJ, Chen CT et al (2007) The quest for highperformance host materials for electrophosphorescent blue dopants. Adv Funct Mater 17:1887-1895. https://doi.org/ 10.1002/adfm. 200600800

[34] Huang H, Fu Q, Zhuang S, Liu Y, Wang L, Wang L, Chen J, Ma D, Yang C (2011) Novel deep blue OLED emitters with 1,3,5-Tri(anthracen-10-yl)benzene- centered starburst oligofluorenes. J Phys Chem C 115:4872-4878. https://doi. org/10.1021/jp110652y

[35] Xiao L, Su SJ, Agata Y, Lan H, Kido J (2009) Nearly 100\% internal quantum efficiency in an organic blue-light electrophosphorescent device using a weak electron transporting material with a wide energy gap. Adv Mater 21:1271-1274. https://doi.org/10.1002/adma.200802034

[36] Chen Z, Zhang H, Du X, Cheng X, Chen X, Jiang Y, Yang B (2013) From planar-heterojunction to n-i structure: an efficient strategy to improve short-circuit current and power conversion efficiency of aqueous-solution-processed hybrid solar cells. Energy Environ Sci 6:1597-1603. https://doi. org/10.1039/c3ee40481a

[37] Zhang S, Ye L, Hou J (2016) Breaking the 10\% efficiency barrier in organic photovoltaics: morphology and device optimization of well-known PBDTTT polymers. Adv Energy Mater 6:1-20. https://doi.org/10.1002/aenm. 201502529

[38] Liu N, Mei S, Sun D et al (2019) Effects of charge transport materials on blue fluorescent organic light-emitting diodes with a host-dopant system. Micromachines 10:1-10. http s://doi.org/10.3390/mi10050344

[39] Purvis LJ, Gu X, Ghosh S, Zhang Z, Cramer CJ, Douglas CJ (2018) Synthesis and characterization of electron-deficient asymmetrically substituted diarylindenotetracenes. J Org Chem 83:1828-1841. https://doi.org/10.1021/acs.joc. $7 \mathrm{~b} 02756$ 
[40] Hughes G, Bryce MR (2005) Electron-transporting materials for organic electroluminescent and electrophosphorescent devices. J Mater Chem 15:94-107. https://doi.org/ 10.1039/b413249c

[41] Usta H, Kim C, Wang Z, Lu S, Huang H, Facchetti A, Marks TJ (2012) Anthracenedicarboximide-based semiconductors for air-stable, n-channel organic thin-film transistors: materials design, synthesis, and structural characterization. J Mater Chem 22:4459-4472. https://doi. org/10.1039/c1jm14713g

[42] Hendsbee AD, Sun JP, Rutledge LR, Hill LG, Welch GC (2014) Electron deficient diketopyrrolopyrrole dyes for organic electronics: synthesis by direct arylation, optoelectronic characterization, and charge carrier mobility. J Mater Chem A 2:4198-4207. https://doi.org/10.1039/c3ta $14414 \mathrm{c}$

[43] Zhang Z, Yuan J, Wei Q, Zou Y (2018) Small-molecule electron acceptors for efficient non-fullerene organic solar cells. Front Chem 6:414-471. https://doi.org/10.3389/fche m.2018.00414

[44] Park H, Shin DS, Yu HS, Chae HB (2007) Electron mobility in tris(8-hydroxyquinoline)aluminum $\left(\mathrm{Alq}_{3}\right)$ films by transient electroluminescence from single layer organic light emitting diodes. Appl Phys Lett 90:67-70. https://doi. org/10.1063/1.2734386

[45] Kao PC, Chiu CT (2015) $\mathrm{MoO}_{3}$ as p-type dopant for $\mathrm{Alq}_{3^{-}}$ based p- $i$-n homojunction organic light-emitting diodes. Org Electron 26:443-450. https://doi.org/10.1016/j.orgel.2 015.08 .018

[46] Bo CL, Cheng CP, You ZQ, Hsu CP (2005) Charge transport properties of tris(8-hydroxyquinolinato)aluminum(III): why it is an electron transporter. J Am Chem Soc 127:66-67. https://doi.org/10.1021/ja045087t

[47] Li C, Li T, Li A, Cui G, Zhang R, Liu S (2010) Performance enhanced OLEDs using a $\mathrm{Li}_{3} \mathrm{~N}$ doped tris(8-hydroxyquinoline) aluminum $\left(\mathrm{Alq}_{3}\right)$ thin film as electroninjecting and transporting layer. Symp Photonics Optoelectron SOPO 2010 - Proc 8-11. https://doi.org/10.1109/ SOPO.2010.5504074

[48] Kolosov D, Adamovich V, Djurovich P, Thompson ME (2002) 1, 8-Naphthalimides in phosphorescent organic LEDs: the interplay between dopant, exciplex, and host emission. J Am Chem Soc 124:9945-9954. https://doi.org/ 10.1021/ja0263588

[49] Pope M, Burgos J (1966) Charge-transfer exciton state and ionic energy levels in anthracene crystal. Mol Cryst 1:395-415. https://doi.org/10.1080/15421406608083280

[50] Brutting W (2006) Physics of organic semiconductors, 2nd edn. Wiley-VCH
[51] Li H, Choi J, Nakanishi T (2013) Optoelectronic functional materials based on alkylated- $\pi$ molecules: self-assembled architectures and nonassembled liquids. Langmuir 29:5394-5406. https://doi.org/10.1021/la400202r

[52] Elbing M, Bazan GC (2008) A new design strategy for organic optoelectronic materials by lateral boryl substitution. Angew Chemie - Int Ed 47:834-838. https://doi.org/ 10.1002/anie.200703722

[53] Kulkarni AP, Tonzola CJ, Babel A (2004) Electron transport materials for organic light-emitting diodes. Chem Mater 14:4556-4573. https://doi.org/10.1021/cm0494731

[54] Sasabe H, Gonmori E, Chiba T et al (2008) Wide-energygap electron-transport materials containing 3,5-dipyridylphenyl moieties for an ultra high efficiency blue organic light-emitting device. Chem Mater 20:5951-5953. https://d oi.org/10.1021/cm801727d

[55] Yoo SJ, Yun HJ, Kang I, Thangaraju K, Kwon SK, Kim YH (2013) A new electron transporting material for effective hole-blocking and improved charge balance in highly efficient phosphorescent organic light emitting diodes. J Mater Chem C 1:2217-2223. https://doi.org/10.1039/c3tc00801k

[56] Chen S, Zeng P, Wang W, Wang X, Wu Y, Lin P, Peng Z (2019) Naphthalimide-arylamine derivatives with aggregation induced delayed fluorescence for realizing efficient green to red electroluminescence. J Mater Chem C 7:2886-2897. https://doi.org/10.1039/C8TC06163G. Volume

[57] Martin E, Weigand R, Pardo A (1996) Solvent dependence of the inhibition of intramolecular charge-transfer in $\mathrm{N}$ substituted 1,8-naphthalimide derivatives as dye lasers. J Lumin 68:157-164. https://doi.org/10.1016/0022-2313(9 6)00008-7

[58] Stewart WW (1981) Synthesis of 3,6-disulfonated 4-aminonaphthalimides. J Am Chem Soc 103:7616. http s://doi.org/10.1021/ja00415a033

[59] Ventura B, Bertocco A, Braga D, Catalano L, d'Agostino S, Grepioni F, Taddei P (2014) Luminescence properties of 1,8-naphthalimide derivatives in solution, in their crystals, and in co-crystals: toward room-temperature phosphorescence from organic materials. J Phys Chem C 118:18646-18658. https://doi.org/10.1021/jp5049309

[60] Fu Y, Pang XX, Wang ZQ, Qu HT, Ye F (2018) Synthesis and fluorescent property study of novel 1,8-naphthalimidebased chemosensors. Molecules 23:1-14. https://doi.org/1 0.3390/molecules23020376

[61] Gudeika D, Grazulevicius JV, Volyniuk D, Juska G, Jankauskas V, Sini G (2015) Effect of ethynyl linkages on the properties of the derivatives of triphenylamine and 1,8naphthalimide. J Phys Chem C 119:28335-28346. https://d oi.org/10.1021/acs.jpcc.5b10163 
[62] Ulla H, Kiran MR, Garudachari B, Satyabarayan MN, Umesh G, Isloor AM (2014) Blue emitting halogen-phenoxy substituted 1,8-naphthalimides for potential organic light emitting diode applications. Opt Mater (Amst) 37:311-321. https://doi.org/10.1016/j.optmat.2014.06.016

[63] Jiang W, Sun Y, Wang X, Wang Q, Xu W (2008) Synthesis and photochemical properties of novel 4-diarylamine-1,8naphthalimide derivatives. Dye Pigment 77:125-128. http s://doi.org/10.1016/j.dyepig.2007.03.017

[64] Xiao P, Dumur F, Graff B, Gigmes D, Fouassier JP, Lalevee J (2014) Blue light sensitive dyes for various photopolymerization reactions: Naphthalimide and naphthalic anhydride derivatives. Macromolecules 47:601-608. https://doi. org/10.1021/ma402376x

[65] Zhang J, Xiao H, Zhang X et al (2016) 1,8-Naphthalimidebased nonfullerene acceptors for wide optical band gap polymer solar cells with an ultrathin active layer thickness of $35 \mathrm{~nm}$. J Mater Chem C 4:5656-5663. https://doi.org/10. 1039/c6tc01438k

[66] Saha S, Samanta A (2002) Influence of the structure of the amino group and polarity of the medium on the photophysical behavior of 4-amino-1,8-naphthalimide derivatives. J Phys Chem A 106:4763-4771. https://doi.org/10. 1021/jp013287a

[67] Han DM, Song HJ, Han CH, Kim YS (2015) Enhancement of the outdoor stability of dye-sensitized solar cells by a spectrum conversion layer with 1,8-naphthalimide derivatives. RSC Adv 5:32588-32593. https://doi.org/10.1039/c 5ra03908h

[68] Wang Y, Zhang X, Han B et al (2010) The synthesis and photoluminescence characteristics of novel blue lightemitting naphthalimide derivatives. Dye Pigment 86:190-196. https://doi.org/10.1016/j.dyepig.2010.01.003

[69] Marinova NV, Georgiev NI, Bojinov VB (2013) Facile synthesis, sensor activity and logic behaviour of 4-aryloxy substituted 1,8-naphthalimide. J Photochem Photobiol A Chem 254:54-61. https://doi.org/10.1016/j.jphotochem.20 13.01 .008

[70] Xu Z, Qian X, Cui J, Zhang R (2006) Exploiting the deprotonation mechanism for the design of ratiometric and colorimetric $\mathrm{Zn}^{2+}$ fluorescent chemosensor with a large red-shift in emission. Tetrahedron 62:10117-10122. http s://doi.org/10.1016/j.tet.2006.08.050

[71] Pfeffer FM, Buschgens AM, Barnett NW, Gunnlaugsson T, Kruger P (2005) 4-Amino-1,8-naphthalimide-based anion receptors: employing the naphthalimide $\mathrm{N}-\mathrm{H}$ moiety in the cooperative binding of dihydrogenphosphate. Tetrahedron Lett 46:6579-6584. https://doi.org/10.1016/j.tetlet.2005.07. 067
[72] Zhu W, Xu Y, Zhang Y, Jianping S, He T (2005) Singlet energy transfer and photoinduced electron transfer in starshaped naphthalimide derivatives based on triphenylamine. Bull Chem Soc Jpn 78:1362-1367. https://doi.org/10.124 6/bcsj.78.1362

[73] Xie Z, Yang B, Cheng G, Liu L, He F, Shen F, Ma Y, Liu S (2005) Supramolecular interactions induced fluorescence in crystal : anomalous emission of 2, 5-diphenyl-1, 4-distyrylbenzene with all cis double bonds. Communications 17:1287-1289. https://doi.org/10.1021/cm048400z

[74] Dong Y, Xu B, Zhang J et al (2012) Piezochromic luminescence based on the molecular aggregation of 9,10Bis((E)-2-(pyrid-2-yl)vinyl)anthracene. Angew Chemie Int Ed 51:10782-10785. https://doi.org/10.1002/anie. 201204660

[75] Ulla H, Garudachar B, Satyanarayan MN, Umesh G, Isloor AM (2013) Blue light emitting naphthalimides for organic light emitting diodes. AIP Conf Proc 1512:1300-1301. h ttps://doi.org/10.1063/1.4791530

[76] Liu J, Li Y, Wang Y, Sun H, Lu Z, Wu H, Peng J, Huang Y (2012) Synthesis and luminescent properties of blue sextuple-hydrogen-bond self-assembly molecular duplexes bearing 4-phenoxy-1,8-naphthalimide moieties. Opt Mater (Amst) 34:1535-1542. https://doi.org/10.1016/j.optmat.20 12.03 .022

[77] Ulla H, Garudachari B, Satyanarayan MN, Umesh G (2012) Isloor AM (2012) Blue light emitting materials for organic light emitting diodes: experimental and simulation study. Int Conf Opt Eng ICOE 978:6-9. https://doi.org/10.1109/ ICOE.2012.6409561

[78] Zhang W, Xu Y, Hanif M, Zhang S, Zhou J, Hu D, Xie Z, Ma Y (2017) Enhancing fluorescence of naphthalimide derivatives by suppressing the intersystem crossing. J Phys Chem C 121:23218-23223. https://doi.org/10.1021/acs.jpc c. $7 \mathrm{~b} 07513$

[79] Ledwon P, Brzeczek A, Pluczyk S, Jarosz T, Kuznik W, Walczak K, Lapkowski M (2014) Synthesis and electrochemical properties of novel, donor-acceptor pyrrole derivatives with 1,8-naphthalimide units and their polymers. Electrochim Acta 128:420-429. https://doi.org/10.1 016/j.electacta.2013.10.163

[80] Arunchai R, Sudyoadsuk T, Prachumrak N, Namuangruk S, Promarak V, Sukwattanasinitt M, Rashatasakhan P (2015) Synthesis and characterization of new triphenylamino-1,8naphthalimides for organic light-emitting diode application. New J Chem 39:2807-2814. https://doi.org/10.1039/ C4NJ01785D

[81] Tang CW, Vanslyke SA (1987) Organic electroluminescent diodes. Appl Phys Lett 51:913-915. https://doi.org/10.106 3/1.98799 
[82] Van Slyke SA, Chen CH, Tang CW (1996) Organic electroluminescent devices with improved stability. Appl Phys Lett 69:2160-2162. https://doi.org/10.1063/1.117151

[83] Liu J, Chen CT, Chen CH (2015) Introduction to organic light-emitting diode (OLED). Wiley online library. https://d oi.org/10.1002/9781118798706.hdi022

[84] Ferreira R, Baleizao C, Muñoz-Molina JM, Pischel U (2011) Photophysical study of bis(naphthalimide)-amine conjugates: toward molecular design of excimer emission switching. J Phys Chem A 115:1092-1099. https://doi.org/ 10.1021/jp110470h

[85] Saini A, Thomas KRJ, Sachdev A, Gopinath P (2017) Photophysics, electrochemistry, morphology, and bioimaging applications of new 1,8-naphthalimide derivatives containing different chromophores. Chem - An Asian J 12:2612-2622. https://doi.org/10.1002/asia.201700968

[86] Bekere L, Gachet D, Lokshin V, Marine W, Khodorkovsky V (2013) Synthesis and spectroscopic properties of 4-amino-1,8-naphthalimide derivatives involving the carboxylic group: a new molecular probe for $\mathrm{ZnO}$ nanoparticles with unusual fluorescence features. Beilstein J Org Chem 9:1311-1318. https://doi.org/10.3762/bjoc.9.147

[87] Katz HE, Lovinger AJ, Johnson J, Kloc C, Siegrist T, Li W, Lin YY, Dodabalapur A (2000) A soluble and airstable organic semiconductor with high electron mobility. Nature 404:478-481. https://doi.org/10.1038/35006603

[88] Liu B, Tian H (2005) A ratiometric fluorescent chemosensor for fluoride ions based on a proton transfer signaling mechanismt. J Mater Chem 15:2681-2686. http s://doi.org/10.1039/b501234a

[89] Qi X, Slootsky M, Forrest S (2008) Stacked white organic light emitting devices consisting of separate red, green, and blue elements. Appl Phys Lett 93:4-7. https://doi.org/10. 1063/1.3021014

[90] Chopra N, Lee J, Zheng Y, Eom SH, Xue J, So F (2008) High efficiency blue phosphorescent organic light-emitting device. Appl Phys Lett 93:1-4. https://doi.org/10.1063/1. 3000382

[91] Zhang Z, Wang Q, Dai Y, Liu Y, Wang L, Ma D (2009) High efficiency fluorescent white organic light-emitting diodes with red, green and blue separately monochromatic emission layers. Org Electron 10:491-495. https://doi.org/ 10.1016/j.orgel.2009.02.006

[92] Fan J, Yung K, Pecht M (2014) Prognostics of lumen maintenance for High power white light emitting diodes using a nonlinear filter-based approach. Reliab Eng Syst Saf 123:63-72. https://doi.org/10.1016/j.ress.2013.10.005

[93] Das D, Gopikrishna P, Barman D, Yathirajila RB, Iyer PK (2019) White light emitting diode based on purely organic fluorescent to modern thermally activated delayed fluorescence (TADF) and perovskite materials. Nano Converg 6:1-28. https://doi.org/10.1186/s40580-019-0201-6

[94] Chiba T, Pu Y-J, Kido J (2018) White OLED (WOLED) and charge generation layer (CGL). Handb Org Light Diodes. https://doi.org/10.1007/978-4-431-55761-6_20-1

[95] Yang SH, Huang TL (2021) High fluorescence efficiency of dual-wavelength white OLED with NPB emission and triplet annihilation. Opt Mater (Amst) 111:110725. https://doi. org/10.1016/j.optmat.2020.110725

[96] Ulla H, Garudachari B, Satyanarayan MN, Umesh G, Isloor AM (2014) Blue organic light emitting materials: synthesis and characterization of novel 1, 8-naphthalimide derivatives. Opt Mater (Amst) 36:704-711. https://doi.org/10.10 16/j.optmat.2013.11.017

[97] Ulla H, Kiran MR, Garudachari B, Ahipa TN, Tarafder K, Adhikari AV, Umesh G, Satyanarayan MN (2017) Blue emitting 1,8-naphthalimides with electron transport properties for organic light emitting diode applications. J Mol Struct 1143:344-354. https://doi.org/10.1016/j.molstruc.20 17.04.103

[98] Boonnab S, Chaiwai C, Nalaoh P, Manyum T (2021) Synthesis, characterization, and physical properties of pyrene-naphthalimide derivatives as emissive materials for electroluminescent devices. European J Org Chem 2021:2402-2410. https://doi.org/10.1002/ejoc.202100134

[99] Mohan M, John R, Nagarajan SM, Trivedi DR (2020) Design, synthesis and characterization of $N$-substituted heteroaromatics: DFT-studies and organic light emitting device application. ChemistrySelect 5:5903-5915. https://d oi.org/10.1002/slct.201903409

[100] Wang S, Zeng PJ, Liu YQ, Yu G, Sun XB, Niu HB, Zhu DB (2005) Luminescent properties of a novel naphthalimide-fluorene molecule. Synth Met 150:33-38. https://doi. org/10.1016/j.synthmet.2004.12.019

[101] Zhu W, Hu M, Yao R, Tian H (2003) A novel family of twisted molecular luminescent materials containing carbazole unit for single-layer organic electroluminscent devices. J Photochem Photobiol A Chem 154:169-177. h ttps://doi.org/10.1016/S1010-6030(02)00325-8

[102] Zagranyarski Y, Mutovska M, Petrova P, Tomova R, Ivanov P, Stoyanov S (2020) Dioxin-annulated 1,8-naphthalimides-synthesis, spectral and electrochemical properties, and application in OLED. Dye Pigment 184:108585. https://doi. org/10.1016/j.dyepig.2020.108585

[103] Mikroyannidis JA, Ye S, Liu Y (2009) Electroluminesent divinylene- and trivinylene-molecules with terminal naphthalimide or phthalimide segments. Synth Met 159:492-500. https://doi.org/10.1016/j.synthmet.2008.11. 009 
[104] Jung SO, Yuan W, Ju JU, Zhang S, Kim YH, Je JT, Kwon SK (2009) A new orange-light-emitting materials based on (N-naphthyl)-1,8- naphthalimide for OLED applications. Mol Cryst Liq Cryst 514:45/[375]-54/[384]. https://doi.org/ $10.1080 / 15421400903217751$

[105] Zeng W, Lai H, Lee W et al (2017) Achieving nearly 30\% external quantum efficiency for orange-red organic light emitting diodes by employing thermally activated delayed fluorescence emitters composed of 1, 8-naphthalimideacridine hybrids. Adv Mater 1704961:1-8. https://doi.org/ 10.1002/adma.201704961

[106] Uoyama H, Goushi K, Shizu K, Nomura H, Adachi C (2012) Highly efficient organic light-emitting diodes from delayed fluorescence. Nature 492:234-238. https://doi.org/ 10.1038/nature11687

[107] Wong MY, Zysman-Colman E (2017) Purely organic thermally activated delayed fluorescence materials for organic light-emitting diodes. Adv Mater 29:1605444. h ttps://doi.org/10.1002/adma.201605444

[108] Chen T, Lu CH, Huang CW et al (2019) Tuning the emissive characteristics of TADF emitters by fusing heterocycles with acridine as donors: highly efficient orange to red organic light-emitting diodes with EQE over $20 \%$. J Mater Chem C 7:9087-9094. https://doi.org/10.1039/c9tc 01973a

[109] Wang YF, Lu HY, Chen C, Li M, Chen CF (2019) 1,8Naphthalimide-based circularly polarized TADF enantiomers as the emitters for efficient orange-red OLEDs. Org Electron 70:71-77. https://doi.org/10.1016/j.orgel.2019.03. 020

[110] Mi BX, Gao ZQ, Liu MW et al (2002) New polycyclic aromatic hydrocarbon dopants for red organic electroluminescent devices. J Mater Chem 12:1307-1310. https://d oi.org/10.1039/b110153f

[111] Zhang YL, Ran Q, Wang Q, Liu Y, Hanish C, Reineke S, Fan J, Liao LS (2019) High-efficiency red organic lightemitting diodes with external quantum efficiency close to $30 \%$ based on a novel thermally activated delayed fluorescence emitter. Adv Mater 31:1-7. https://doi.org/10.10 02/adma.201902368

[112] Lu G, He C, Fang Y, Wang L, Zhu W (2018) Construction of mixed corrole-phthalocyanine europium triple-decker complexes involving: meso-substituted trans $-\mathrm{A}_{2} \mathrm{~B}$-corrole. New J Chem 42:2498-2503. https://doi.org/10.1039/c 7 nj04446a

[113] Nakamura K, Minami H, Sagara A, Itamoto N, Kobayashi N (2018) Enhanced red emissions of europium(III) chelates in DNA-CTMA complexes. J Mater Chem C 6:4516-4522. https://doi.org/10.1039/c8tc00255j
[114] Song B, Wang G, Tan M, Yuan J (2006) A europium(III) complex as an efficient singlet oxygen luminescence probe. J Am Chem Soc 128:13442-13450. https://doi.org/10.102 $1 /$ ja062990f

[115] Vembris A, Zarins E, Jubels J, Kokars V, Muzikante I, Miasojedovas A, Jursenas S (2012) Thermal and optical properties of red luminescent glass forming symmetric and non symmetric styryl-4H-pyran-4-ylidene fragment containing derivatives. Opt Mater (Amst) 34:1501-1506. http s://doi.org/10.1016/j.optmat.2012.02.051

[116] Wang Z, Wang M, Peng J, Liu XY, M, Goa W, Zhou Y, Haung X, Wu H, (2019) Polymorphism and multicolor mechanofluorochromism of a D-p-A asymmetric $4 H$-pyran derivative with aggregation-induced emission property. J Phys Chem C 123:27742-27751. https://doi.org/10.1021 /acs.jpcc.9b06912

[117] Luo S, Lin J, Zhou J, Wang Y, Liu X, Lu Z, Hu C (2015) Novel 1,8-naphthalimide derivatives for standard-red organic light-emitting device applications. J Mater Chem C 3:5259-5267. https://doi.org/10.1039/c5tc00409h

[118] Zhao Z, Geng J, Chang Z et al (2012) A tetraphenylethenebased red luminophor for an efficient non-doped electroluminescence device and cellular imaging. J Mater Chem 22:11018-11021. https://doi.org/10.1039/c2jm31482g

[119] Lee KH, Kim YK, Yoon SS (2012) Trimethylsilane-containing donor-acceptor-donor type material for red fluorescent organic light-emitting diodes. J Nanosci Nanotechnol 12:4203-4206. https://doi.org/10.1166/jnn.20 12.5925

[120] Lee Y, Chiang C, Chen C (2008) Solid-state highly fluorescent diphenylaminospirobifluorenylfumaronitrile red emitters for non-doped organic light-emitting diodes. Chem Commun 2:217-219. https://doi.org/10.1039/b711157f

[121] Kim JH, Yun JH, Lee JY (2018) Recent progress of highly efficient red and near-infrared thermally activated delayed fluorescent emitters. Adv Opt Mater 6:1-16. https://doi.org/ 10.1002/adom.201800255

[122] Zeng W, Lai HY, Lee WK et al (2018) Achieving nearly $30 \%$ external quantum efficiency for orange-red organic light emitting diodes by employing thermally activated delayed fluorescence emitters composed of 1,8-naphthalimide-acridine hybrids. Adv Mater 30:1-8. https://doi.org/ 10.1002/adma.201704961

[123] Gan J, Liang Q, Yuan X, Xiao H, Chen K, Tian H (2004) 1,8-Naphthalimides for non-doping OLEDs: the tunable emission color from blue, green to red. J Photochem Photobiol A Chem 162:399-406. https://doi.org/10.1016/S101 0-6030(03)00381-2

[124] Zhou J, Chen P, Wang X et al (2014) Charge-transfer-featured materials-promising hosts for fabrication of efficient 
OLEDs through triplet harvesting via triplet fusion. Chem Commun 50:7586-7589. https://doi.org/10.1039/c4cc $00576 \mathrm{~g}$

[125] Bezvikonnyi O, Gudeika D, Volyniuk D et al (2018) Pyrenyl substituted 1,8-naphthalimide as a new material for weak efficiency-roll-off red OLEDs: a theoretical and experimental study. New J Chem 42:12492-12502. http s://oi.org/10.1039/c8nj01866a

[126] Wang P, Xie Z, Tong S, Wong O, Lee CS, Wong N, Hung L, Lee $S$ (2003) A novel neutral red derivative for applications in high-performance red-emitting electroluminescent devices. Chem Mater 15:1913-1917. https://doi.org/ $10.1021 / \mathrm{cm} 0209214$

[127] Zhang Q, Sun S, Liu W et al (2019) Integrating TADF luminogens with AIE characteristics using a novel acridinecarbazole hybrid as donor for high-performance and low efficiency roll-off OLEDs. J Mater Chem C 7:9487-9495. h ttps://doi.org/10.1039/c9tc01329f

[128] Zhao Y, Wang W, Gui C et al (2018) Thermally activated delayed fluorescence material with aggregation-induced emission properties for highly efficient organic light-emitting diodes. J Mater Chem C 6:2873-2881. https://doi.org/ $10.1039 / \mathrm{c} 7 \mathrm{tc} 04934 \mathrm{j}$

[129] Rizzo F, Cucinotta F (2018) Recent developments in AIEgens for non-doped and TADF OLEDs. Isr J Chem 58:874-888. https://doi.org/10.1002/ijch.201800049

[130] Hu J, Zhang X, Zhang D, Cao X, Jiang T, Zhang X, Tao Y (2017) Linkage modes on phthaloyl/triphenylamine hybrid compounds: multi-functional AIE luminogens, non-doped emitters and organic hosts for highly efficient solutionprocessed delayed fluorescence OLEDs. Dye Pigment 137:480-489. https://doi.org/10.1016/j.dyepig.2016.10.029

[131] Wu Y, Chen X, Mu Y et al (2019) Two thermally stable and AIE active 1,8-naphthalimide derivatives with red efficient thermally activated delayed fluorescence. Dye Pigment 169:81-88. https://doi.org/10.1016/j.dyepig.2019.04.071

[132] Yun JH, Lee JY (2017) Benzoisoquinoline-1,3-dione acceptor based red thermally activated delayed fluorescent emitters. Dye Pigment 144:212-217. https://doi.org/10.10 16/j.dyepig.2017.05.036

[133] Wang B, Zheng Y, Wang T, Ma D, Wang Q (2021) 1,8Naphthalimide-based hybrids for efficient red thermally activated delayed fluorescence organic light-emitting diodes. Org Electron 88:106012. https://doi.org/10.1016/j. orgel.2020.106012

[134] Tu G, Zhou Q, Cheng Y, Wang L, Ma D, Jing X, Wang F (2004) White electroluminescence from polyfluorene chemically doped with 1,8-napthalimide moieties. Appl Phys Lett 85:2172-2174. https://doi.org/10.1063/1. 1793356
[135] Coya C, Luis A, Ramos M, Gomez R, Seoane C (2012) Highly efficient solution-processed white organic lightemitting diodes based on novel copolymer single layer. Synth Met 161:2580-2584. https://doi.org/10.1016/j.synth met.2011.08.010

[136] Singh J, Baessler H, Kugler S (2008) A direct approach to study radiative emission from triplet excitations in molecular semiconductors and conjugated polymers. A direct approach to study radiative emission from triplet excitations. J Chem Phys 129:041103. https://doi.org/10.1063/1. 2961010

[137] Jin R, Zhang J (2013) Photophysical properties of derivatives of 2-(2-Hydroxyphen-yl)-1,3,4- oxadiazole: a theoretical study. J Phys Chem A 117:8285-8292. https://doi. org/10.1021/jp403643f

[138] Mohamad M, Ahmed R, Shaari A, Goumri-Said S (2015) First principles investigations of vinazene molecule and molecular crystal: a prospective candidate for organic photovoltaic applications. J Mol Model 21:27. https://doi. org/10.1007/s00894-015-2582-8

[139] Chai W, Jin R (2016) Theoretical investigations into optical and charge transfer properties of donor-acceptor 1,8-naphthalimide derivatives as possible organic light-emitting materials. J Mol Struct 1103:177-182. https://doi.org/10. 1016/j.molstruc.2015.09.023

[140] Jin R, Tang S (2013) Theoretical study on optical and electronic properties of bipolar molecules with 1,8-naphthalimide and triphenylamine moieties as organic lightemitting materials. J Mol Graph Model 42:120-128. http s://doi.org/10.1016/j.jmgm.2013.04.001

[141] Sun F, Jin R (2014) Optical and charge transport properties of $N$-butyl-1,8-naphthalimide derivatives as organic lightemitting materials: a theoretical study. J Lumin 149:125-132. https://doi.org/10.1016/j.jlumin.2014.01.011

[142] Jin R, Tang S (2013) Theoretical investigation into optical and electronic properties of 1,8-naphthalimide derivatives. J Mol Model 19:1685-1693. https://doi.org/10.1007/s008 94-012-1734-3

[143] Jin R, Ahmad I (2015) Theoretical study on photophysical properties of multifunctional star-shaped molecules with 1,8-naphthalimide core for organic light-emitting diode and organic solar cell application. Theor Chem Acc 134:89. h ttps://doi.org/10.1007/s00214-015-1693-8

[144] Tao S, Peng Z, Zhang X, Wang PF (2005) Highly efficient non-doped blue organic light-emitting diodes based on fluorene derivatives with high thermal stability. Adv Funct Mater 15:1716-1721. https://doi.org/10.1002/adfm. 200500067

[145] Tong QX, Lai SL, Chan MY et al (2009) A high performance nondoped blue organic light-emitting device based 
on a diphenylfluoranthene-substituted fluorene derivative. J Phys Chem C 113:6227-6230. https://doi.org/10.1021/ jp810305b

[146] Fresta E, Baumgärtner K, Cabanillas-Gonzalez J, Mastalerz M, Costa RD (2020) Bright, stable, and efficient red lightemitting electrochemical cells using contorted nanographenes. Nanoscale Horizons 5:473-480. https://doi.org/ 10.1039/c9nh00641a

[147] Guo H, Muro-Small ML, Ji S, Zhao J, Castellano F (2010) Naphthalimide phosphorescence finally exposed in a platinum(II) diimine complex. Inorg Chem 49:6802-6804. h ttps://doi.org/10.1021/ic101107b

[148] Ishii M, Taga Y (2002) Influence of temperature and drive current on degradation mechanisms in organic light-emitting diodes. Appl Phys Lett 80:3430-3432. https://doi.org/ 10.1063/1.1476704

[149] Ke L, Chua SJ, Zhang K, Yakovlev N (2002) Degradation and failure of organic light-emitting devices. Appl Phys Lett 80:2195-2197. https://doi.org/10.1063/1.1464216
[150] Höfle S, Bernhard C, Bruns M, Kubel C, Scherer T, Lemmer U, Colsmann A (2015) Charge generation layers for solution processed tandem organic light emitting diodes with regular device architecture. ACS Appl Mater Interfaces 7:8132-8137. https://doi.org/10.1021/acsami.5b 00883

[151] Hatwar TK, Spindler JP, Ricks ML et al (2004) High-efficiency white OLEDs based on small molecules. Org Light Mater Devices VII 5214:233-240. https://doi.org/10.1117/ 12.514536

[152] Liu L, Chen F, Xu B, Dong Y, Zhao Z, Tian W, Ping Lu (2010) Solution-processed white organic light-emitting diode based on a single-emitting small molecule. Synth Met 160:1968-1972. https://doi.org/10.1016/j.synthmet.2010.0 7.017

Publisher's Note Springer Nature remains neutral with regard to jurisdictional claims in published maps and institutional affiliations. 